\title{
Quasi-static and dynamic fracture behaviour of rock materials: phenomena and mechanisms
}

\author{
Q. B. Zhang · J. Zhao
}

Received: 16 November 2013 / Accepted: 3 July 2014 / Published online: 24 July 2014

(C) Springer Science+Business Media Dordrecht 2014

\begin{abstract}
An experimental investigation is conducted to study the quasi-static and dynamic fracture behaviour of sedimentary, igneous and metamorphic rocks. The notched semi-circular bending method has been employed to determine fracture parameters over a wide range of loading rates using both a servo-hydraulic machine and a split Hopkinson pressure bar. The time to fracture, crack speed and velocity of the flying fragment are measured by strain gauges, crack propagation gauge and high-speed photography on the macroscopic level. Dynamic crack initiation toughness is determined from the dynamic stress intensity factor at the time to fracture, and dynamic crack growth toughness is derived by the dynamic fracture energy at a specific crack speed. Systematic fractographic studies on fracture surface are carried out to examine the micromechanisms of fracture. This study reveals clearly that: (1) the crack initiation and growth toughness increase with increasing loading rate and crack speed; (2) the kinetic energy of the flying fragments increases with increasing striking speed; (3) the dynamic fracture energy increases

\section{Q. B. Zhang $(\varangle) \cdot$ J. Zhao}

Laboratory of Rock Mechanics (LMR), School of

Architecture, Civil and Environmental Engineering

(ENAC), École Polytechnique Fédérale de Lausanne

(EPFL), 1015 Lausanne, Switzerland

e-mail: qianbing.zhang@gmail.com

URL: http://people.epfl.ch/qianbing.zhang

\section{J. Zhao}

Department of Civil Engineering, Monash University,

Building 60, Clayton, Melbourne, VIC 3800, Australia

rapidly with the increase of crack speed, and a semiempirical rate-dependent model is proposed; and (4) the characteristics of fracture surface imply that the failure mechanisms depend on loading rate and rock microstructure.

Keywords Dynamic loading - Rock materials . Fracture behaviour - Fracture toughness .

Micromeasurement · Failure mechanisms

\section{List of symbols}

a

$A_{\mathrm{B}}$

$A_{\mathrm{S}}$

$A_{\mathrm{I}}(v)$

b

B

$C_{\mathrm{B}}$

$C_{\mathrm{L}}$

$C_{\mathrm{R}}$

$C_{\mathrm{S}}$

$D$

E

$E_{\mathrm{B}}$

$G_{\mathrm{C}}$

$G_{\mathrm{dC}}$

$G_{\mathrm{d}}(t, v)$

I

The notch length

The cross-sectional area of the bar

The cross-sectional area of fracture surface

The function of dynamic fracture

A material constant

The thickness of the specimen Longitudinal wave speed of the bar Longitudinal wave speed Rayleigh wave speed Shear wave speed Fractal dimensions Elastic modulus Young's modulus of the bar Quasi-static fracture energy Dynamic fracture energy Dynamic energy release rate The moment of inertia
\end{abstract}




\begin{tabular}{|c|c|}
\hline$K_{\mathrm{I}}, K_{\mathrm{I}}^{\mathrm{dyn}}(t, v)$ & $\begin{array}{l}\text { Quasi-static, dynamic stress } \\
\text { intensity factor }\end{array}$ \\
\hline$K_{\mathrm{IC}}$ & Fracture toughness \\
\hline$K_{\mathrm{Id}}, K_{\mathrm{ID}}$ & $\begin{array}{l}\text { Mode I dynamic crack initiation, } \\
\text { growth toughness }\end{array}$ \\
\hline$K_{\text {IIC }}, K_{\text {IId }}$ & $\begin{array}{l}\text { Mode II quasi-static, dynamic } \\
\text { fracture toughness }\end{array}$ \\
\hline$\dot{K}_{\mathrm{I}}^{\text {dyn }}$ & Dynamic loading rate \\
\hline$m$ & The mass of one fragment \\
\hline$P$ & The load applied on the specimen \\
\hline$P_{\max }$ & The peak applied load \\
\hline$r_{O O}$ & $\begin{array}{l}\text { Distance of the translational } \\
\text { movement }\end{array}$ \\
\hline $\mathrm{R}$ & The specimen radius \\
\hline $2 S$ & The specimen span \\
\hline$t_{\mathrm{f}}$ & The time to fracture \\
\hline$T, T_{\text {Rot. }}, T_{\text {Tra. }}$ & $\begin{array}{l}\text { The total, rotational and } \\
\text { translational kinetic energies }\end{array}$ \\
\hline$v_{0}$ & $\begin{array}{l}\text { The theoretical characteristic } \\
\text { velocity }\end{array}$ \\
\hline$v$ & Crack speed \\
\hline$v_{\lim }$ & The limiting crack speed \\
\hline$v_{\max }$ & The maximum crack speed \\
\hline$v_{\mathrm{T}}$ & The translational velocity \\
\hline$V_{\text {Str. }}$ & The striking impact speed \\
\hline$W_{\text {In. }}, W_{\text {Re. }}, W_{\text {Tr. }}$ & $\begin{array}{l}\text { The energies of the incident, } \\
\text { reflected and transmitted wave }\end{array}$ \\
\hline$W_{\mathrm{S}}$ & $\begin{array}{l}\text { The energy absorbed by the } \\
\text { specimen }\end{array}$ \\
\hline$Y_{\mathrm{I}}(\mathrm{S} / R)$ & The mode-I geometry factor \\
\hline$v$ & The Poisson's ratio \\
\hline$\xi$ & The covering length \\
\hline$N(\xi)$ & The total number of covering box \\
\hline$\delta$ & The critical distance \\
\hline$\delta_{\mathrm{f}}$ & The displacement of fracture \\
\hline$\sigma_{\text {In. }}, \sigma_{\text {Re. }}, \sigma_{\mathrm{Tr} .}$ & $\begin{array}{l}\text { The stress measured by gauges on } \\
\text { incident, reflected and transmitted } \\
\text { bars }\end{array}$ \\
\hline$\omega$ & The angular velocity \\
\hline$\theta$ & The rotational angle \\
\hline$\rho$ & Density \\
\hline$\Omega$ & The dissipated energy \\
\hline
\end{tabular}

\section{Introduction}

Mechanical properties and fracture behaviour of rock materials are influenced by loading rate, and in particular the responses distinguishably change after the load- ing rate exceeds a critical value (Backers et al. 2003; Bazant et al. 1993; Cadoni 2010; Clayton 2010; Hoek and Bieniawski 1965; Kipp et al. 1980; Li et al. 2014; Wong et al. 2014; Zhang and Wong 2013; Zhang and Zhao 2013a, b, 2014; Zhao et al. 1999). The significant differences between quasi-static and dynamic fracture behaviour are traced to specific fracturing process and failure mechanisms.

Table 1 lists the loading rates and the estimate of the time to fracture achieved by various loading techniques for rock materials. The subcritical and quasistatic fracture behaviours of rocks are quite well understood by the double torsion (DT) testing method (Atkinson 1987; Nara et al. 2010). The International Society for Rock Mechanics (ISRM) has suggested four standardized methods: chevron bend (CB) and short rod (SR) methods (Ouchterlony 1988), cracked chevron notched Brazilian disc (CCNBD) method (Fowell 1995), and notched semi-circular bending (NSCB) method (Kuruppu et al. 2014), for the determination of quasi-static fracture toughness. However, the studies on fracture behaviour under dynamic loading have been less investigated (Zhang and Zhao 2014). The dynamic testing methods are basically extended from the corresponding quasi-static ones and categorized approximately into Brazilian disc (BD), compact tension (CT) and bending type methods, as summarized in Table 2. At intermediate loading rates, due to the complication of data processing, only a limited amount of research has been performed, such as the single edge notch bending (SENB) method on granite by means of a pneumatic-hydraulic machine (Zhao et al. 1999), the SENB methods on rock (Yang et al. 2009) and coal (Zhao et al. 2013) using drop-weight machines, and the SR method on oil shale using an instrumented Charpy impact machine (Costin 1981). At high loading rates, the split Hopkinson pressure bar (SHPB) has been used substantially, especially combining with highspeed optical measurement techniques (see Table 2); at a higher loading rate, a projectile impact technique has been applied to determine the dynamic crack initiation and growth toughness of limestone (Bertram and Kalthoff 2003). To the best of our knowledge, no systematic experimental studies have been performed to study fracture behaviour of rocks over a wide range of loading rates on both macroscopic and microscopic scales. The following issues still need to be addressed: (1) detection of the time to fracture, crack speed and velocity of the flying fragment; (2) determination of 
Table 1 Range of loading rates and time to fracture from various experimental techniques for rock materials (after Ravi-Chandar 2004 and Zhang and Zhao 2014)

\begin{tabular}{|c|c|c|c|c|c|c|}
\hline \multirow{3}{*}{$\begin{array}{l}\text { Loading } \\
\text { conditions }\end{array}$} & \multirow{3}{*}{$\begin{array}{l}\text { Quasi- } \\
\text { static } \\
\begin{array}{l}\text { Servo- } \\
\text { hydraulic } \\
\text { machine }\end{array}\end{array}$} & \multicolumn{5}{|l|}{ Dynamic } \\
\hline & & \multicolumn{3}{|c|}{ Intermediate loading rate } & \multicolumn{2}{|c|}{ High loading rate } \\
\hline & & $\begin{array}{l}\text { Pneumatic- } \\
\text { hydraulic } \\
\text { machine }\end{array}$ & $\begin{array}{l}\text { Drop- } \\
\text { weight } \\
\text { machine }\end{array}$ & $\begin{array}{l}\text { Charpy } \\
\text { impact } \\
\text { machine }\end{array}$ & $\begin{array}{l}\text { Split } \\
\text { Hopkinson } \\
\text { bar }\end{array}$ & $\begin{array}{l}\text { Projectile } \\
\text { impact } \\
\text { technique }\end{array}$ \\
\hline $\begin{array}{l}\text { Loading } \\
\text { rate } \\
\dot{K}_{\mathrm{I}}^{\text {dyn }} \\
(\mathrm{MPa} \sqrt{\mathrm{m}} / \mathrm{s})\end{array}$ & 1 & $10^{1}-10^{3}$ & $10^{4}$ & $10^{4}$ & $10^{4}-10^{6}$ & $10^{4}-10^{8}$ \\
\hline $\begin{array}{l}\text { Time to } \\
\text { fracture } \\
t_{\mathrm{f}}(\mu \mathrm{s})\end{array}$ & $>10^{6}$ & $10^{5}-10^{3}$ & $\sim 100$ & $\sim 100$ & $1-100$ & $1-100$ \\
\hline
\end{tabular}

the dynamic crack initiation and propagation toughness; (3) estimate of the dynamic fracture energy; and (4) qualitative and quantitative micromeasurement of the fracture surface.

In this paper, attempts are made to explore the topic of quasi-static and dynamic fracture behaviour of rock materials by considering the fracturing process and failure micromechanisms. The experimental procedures from which the characterizations of fracturing process are derived are briefly described. A detailed description of experimental observations on the macroscopic scale is presented, which are compared with the results reported in the literature. The fractography and surface roughness at the microscopic level are comprehensively examined.

\section{Experimental procedures}

\subsection{Material characterizations}

In order to compare with the previous studies, four types of rock materials that were well studied in dynamic fracture tests were selected for experiments in this paper, namely one sedimentary rock [calcareous sandstone (Yin et al. 2012; Gong and Zhao 2014)], one igneous rock [Fangshan gabbro (Zhang et al. 1999, 2001)], and two metamorphic rocks [Ya' an coarsegrained marble (Wang et al. 2010, 2011) and Fangshan fine-grained marble (Zhang et al. 1999, 2000; Zhang and Zhao 2013a)]. Figure 1 shows the scanned images of thin-section at a resolution of 2,400 dpi and the optical cross-polarized micrographs. The mineralogical compositions and grain sizes are given in Table 3.
The physical and mechanical properties are presented in Table 4. The longitudinal and shear wave speeds were obtained by measuring the transit time of a pulse to travel twice a specimen thickness, and the mechanical properties were determined by uniaxial compression tests.

\subsection{Testing method and measurement techniques}

In the present study, the ISRM-suggested NSCB methods (Kuruppu et al. 2014; Zhou et al. 2012) were employed to investigate the quasi-static and dynamic fracture behaviour of rocks. The specimens of each rock were drilled from one large block. Rock cores with a nominal diameter of $50 \mathrm{~mm}$ were drilled and sliced to obtain discs with an average thickness of $20 \mathrm{~mm}$. The disk was split along the diameter into two semicircular specimens and then a $5 \mathrm{~mm}$ long edge notch was cut using a high-speed diamond impregnated circular blade $(\sim 0.3 \mathrm{~mm}$ thickness). The notch tip was sharpened using a diamond wire saw $(\sim 0.1 \mathrm{~mm}$ thickness) to achieve a sharp crack tip.

The quasi-static tests were performed using a servohydraulic machine at the loading rate of $0.002 \mathrm{~mm} / \mathrm{s}$. The dynamic fracture tests were carried out by means of a SHPB system, and the schematic representation of the experimental setup is shown in Fig. 2a. To study systematically the effect of loading rate, the striker was launched by a gas gun at speeds ranging from 2.0 to $5.0 \mathrm{~m} / \mathrm{s}$. Figure $2 \mathrm{~b}$ shows the photograph of loading configurations and a NSCB specimen with random speckle patterns on the surface that was applied to ensure good contrast of the images for the calcu- 
Table 2 Summary of testing methods for the determination of fracture toughness under both quasi-static and dynamic loading conditions (after Zhang and Zhao 2014)

\begin{tabular}{|c|c|c|c|c|c|c|c|}
\hline Classification & $\begin{array}{l}\text { Testing } \\
\text { methods }^{\mathrm{a}}\end{array}$ & $\begin{array}{l}\text { Quasi- } \\
\text { static } \\
\text { fracture } \\
\text { toughness }\end{array}$ & $\begin{array}{l}\text { Dynamic fracture } \\
\text { toughness }^{\text {b }}\end{array}$ & $\begin{array}{l}\text { Loading } \\
\text { technique }\end{array}$ & Rock type & $\begin{array}{l}\text { Calculation } \\
K_{\mathrm{I}}^{\text {dyn }}(t ; v)\end{array}$ & $\begin{array}{l}\text { Detection } \\
\text { of } t_{\mathrm{f}} \mathrm{d}\end{array}$ \\
\hline \multirow[t]{5}{*}{$\begin{array}{l}\text { Brazilian } \\
\text { disc }\end{array}$} & CST(F)BD & $\begin{array}{l}K_{\mathrm{IC}}, K_{\mathrm{IIC}} \\
\quad \text { (Atkinson et al. } \\
1982 \text { ) }\end{array}$ & $\begin{array}{l}K_{\mathrm{Id}}, K_{\text {IId }} \\
\quad \text { (Nakano et al. } \\
1994)\end{array}$ & $\begin{array}{r}\text { One-bar } \\
\text { SHPB }\end{array}$ & Ceramic & $\begin{array}{l}\text { Finite } \\
\text { element } \\
\text { method }\end{array}$ & $\begin{array}{l}\text { Strain } \\
\text { gauge }\end{array}$ \\
\hline & & & $\begin{array}{l}K_{\text {Id }}, K_{\text {IId }} \text { (Wang } \\
\quad \text { et al. 2011) }\end{array}$ & $\begin{array}{c}\text { Two-bar } \\
\text { SHPB }\end{array}$ & Marble & & \\
\hline & $\mathrm{HC}(\mathrm{F}) \mathrm{BD}$ & $\begin{array}{l}K_{\text {IC }} \text { (Fischer et } \\
\text { al. 1996) }\end{array}$ & $\begin{array}{l}K_{\text {Id }} \text { (Wang et al. } \\
2010)\end{array}$ & & Marble & & \\
\hline & & & $\begin{array}{l}K_{\text {Id }}(\text { Lambert } \\
\text { and Ross 2000) }\end{array}$ & & Concrete & & HS-camera \\
\hline & CCNBD & $\begin{array}{c}K_{\text {IC }}(\text { Fowell } \\
1995)\end{array}$ & $\begin{array}{l}K_{\text {Id }} \text { (Dai et al. } \\
\text { 2010a) }\end{array}$ & & Granite & $\begin{array}{l}\text { Quasi- } \\
\text { static } \\
\text { theory }\end{array}$ & Peak load \\
\hline \multirow[t]{4}{*}{$\begin{array}{c}\text { Compact } \\
\text { tension }\end{array}$} & WLCT & $\begin{array}{c}K_{\text {IC }}(\text { Klepaczko } \\
\text { et al. 1984) }\end{array}$ & $\begin{array}{c}K_{\text {Id }}(\text { Klepaczko } \\
\text { et al. 1984) }\end{array}$ & $\begin{array}{c}\text { Two-bar } \\
\text { SHPB }\end{array}$ & Coal & & \\
\hline & & & $\begin{array}{l}K_{\text {Id }}(\text { Eremenko } \\
\text { et al. 1996) }\end{array}$ & & Granite & & \\
\hline & SR & $\begin{array}{l}K_{\text {IC }} \\
\text { (Ouchterlony } \\
1988)\end{array}$ & $\begin{array}{l}K_{\text {Id }}(\text { Costin } \\
1981)\end{array}$ & $\begin{array}{l}\text { Charpy } \\
\text { impact } \\
\text { machine }\end{array}$ & Oil shale & & \\
\hline & & & $\begin{array}{l}K_{\text {Id }} \text { (Zhang et al. } \\
2000)\end{array}$ & $\begin{array}{c}\text { Two-bar } \\
\text { SHPB }\end{array}$ & $\begin{array}{l}\text { Gabbro, } \\
\text { marble }\end{array}$ & & Moiré \\
\hline \multirow[t]{9}{*}{ Bending } & SENB & $\begin{array}{l}K_{\mathrm{IC}}(\mathrm{ASTM} \\
2011)\end{array}$ & $\begin{array}{l}K_{\text {Id }} \text { (Yang et al. } \\
2009)\end{array}$ & $\begin{array}{l}\text { Drop } \\
\text { weight } \\
\text { machine }\end{array}$ & Rock & $\begin{array}{c}\text { Transverse } \\
\text { diameter }\end{array}$ & $\begin{array}{l}\text { Reflected } \\
\text { caustic }\end{array}$ \\
\hline & & & $\begin{array}{l}K_{\text {Id }}(\text { Zhao et al. } \\
2013)\end{array}$ & & Coal & $\begin{array}{l}\text { Quasi- } \\
\text { static } \\
\text { theory }\end{array}$ & \\
\hline & & & $\begin{array}{l}K_{\text {Id }} \text { (Mindess et } \\
\text { al. 1987) }\end{array}$ & & Concrete & & Peak load \\
\hline & & & $\begin{array}{l}K_{\text {Id }}(\text { Zhao et al. } \\
1999)\end{array}$ & $\begin{array}{l}\text { Pneumatic- } \\
\text { hydraulic } \\
\text { machine }\end{array}$ & Granite & & \\
\hline & & & $\begin{array}{c}K_{\text {Id }}(\text { Tang and } \\
\text { Xu 1990) }\end{array}$ & $\begin{array}{r}\text { One-bar } \\
\text { SHPB }\end{array}$ & Marble & & $\begin{array}{l}\text { Light } \\
\text { passing- } \\
\text { detector } \\
\text { technique }\end{array}$ \\
\hline & CCNSCB & $\begin{array}{l}K_{\text {IC }} \text { (Kuruppu } \\
1997)\end{array}$ & $\begin{array}{l}K_{\text {Id }} \text { (Dai et al. } \\
2011)\end{array}$ & $\begin{array}{l}\text { Two-bar } \\
\text { SHPB }\end{array}$ & Granite & & Peak load \\
\hline & NSCB & $\begin{array}{l}K_{\text {IC }} \text { (Kuruppu et } \\
\text { al. 2014) }\end{array}$ & $\begin{array}{l}K_{\text {Id }}(\text { Chen et al. } \\
2009)\end{array}$ & & Granite & & \\
\hline & & & $\begin{array}{l}K_{\text {ID }}(\text { Chen et al. } \\
2009)\end{array}$ & & Granite & & $\begin{array}{l}\text { LGG, HS- } \\
\text { camera }\end{array}$ \\
\hline & & & $\begin{array}{c}K_{\text {Id }}(\text { Zhang and } \\
\text { Zhao 2013a) }\end{array}$ & & Marble & & $\begin{array}{l}\text { SG, HS- } \\
\text { camera }\end{array}$ \\
\hline
\end{tabular}

${ }^{\text {a }} C S T(F) B D$ cracked straight through (flattened) BD, $H C(F) B D$ holed-cracked FBD, $W L C T$ wedge loaded CT, SENB single edge notch bending, $C C N S C B$ cracked chevron NSCB

${ }^{\text {b }} K_{\text {Id }}, K_{\mathrm{ID}}$ : Mode I dynamic crack initiation, growth toughness. $K_{\text {IId }}$ : Mode II dynamic crack initiation toughness

${ }^{\mathrm{c}} K_{\mathrm{I}}^{\mathrm{dyn}}(t ; v)$ : Dynamic SIF; FEM finite element method

${ }^{\mathrm{d}} S G$ strain gauge, $L G G$ laser gap gauge, $C P G$ crack propagation gauge, $H S$ high-speed 

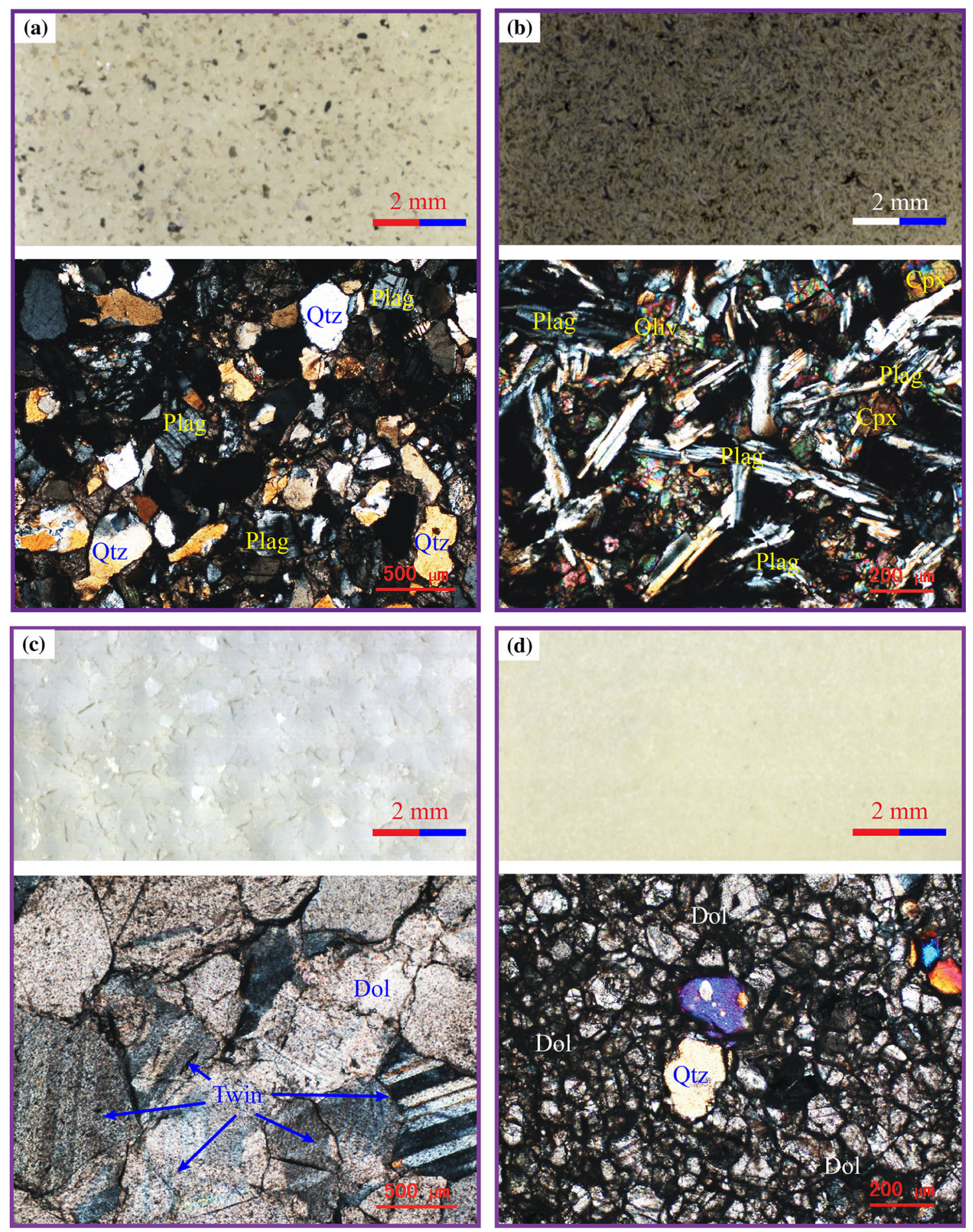

Fig. 1 Scanned images (top) of thin-section at a resolution of 2,400 dpi and cross-polarized micrographs (bottom) of, a sandstone, $\mathbf{b}$ gabbro, $\mathbf{c}$ coarse-grained marble, $\mathbf{d}$ fine-grained marble

(Qtz Quartz, Plag Plagioclase, Oli Olivine, Cpx Clinopyroxene, Dol Dolomite) 
Table 3 Mineralogical composition (MC), composition percentage $(\mathrm{CP})$, maximum grain size (MGS), and average grain size (AGS) of rock materials

\begin{tabular}{lllll}
\hline Rock type $^{\mathrm{a}}$ & MC & CP $(\%)$ & MGS (mm) & AGS (mm) \\
\hline Sandstone & Quartz & $55-62$ & 0.8 & 0.3 \\
& Plagioclase & $32-36$ & 0.6 & \\
\multirow{5}{*}{ Gabbro } & Kfeldspar & $5-8$ & 0.6 & \\
& Plagioclase & $50-60$ & 1.2 & 0.2 \\
& Clinopyroxene & $20-25$ & 1.0 & \\
& Olivine & $6-8$ & 0.4 & \\
& Hornblende & 5 & 0.6 & \\
CG marble & Biotite & 3 & 0.2 & \\
& Dolomite & $92-96$ & 1.9 & 1.2 \\
FG marble & Chert & 3 & 0.8 & \\
& Dolomite & $93-98$ & 0.2 & 0.1 \\
& Quartz & 2 & 0.1 & \\
& Magnetite & 1 & 0.2 & \\
\hline
\end{tabular}

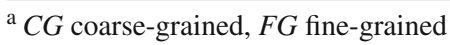

lation of strain fields. A high-speed camera (Photron SA1.1) was located on the front side of the specimen, and a designed electrical circuit with crack propagation gauge or strain gauges were positioned on the back side for calibration. The high-speed camera was operated at the setting: $192 \times 224$ pixels for the size of $26 \times 16 \mathrm{~mm}^{2}$, and 125,000 frames per second. All the signals of strain gauges and the high-speed camera were synchronized with a threshold of the signal captured from the strain gauge on the incident bar. For further details the reader is referred to the previous publication Zhang and Zhao (2013a).

\section{Experimental results}

\subsection{Quasi-static fracture behaviour}

The equation to calculate the stress intensity factor (SIF) $K_{\mathrm{I}}$ of the NSCB specimen is given by Lim et al. (1993)

$$
\begin{array}{r}
K_{\mathrm{I}}=Y_{\mathrm{I}}\left(\frac{\mathrm{S}}{\mathrm{R}}\right) \frac{P \sqrt{\pi \mathrm{a}}}{2 \mathrm{RB}}=\left\{3.638-0.139\left(\frac{\mathrm{a}}{\mathrm{R}}\right)\right. \\
\left.+0.039 \exp \left[7.387\left(\frac{\mathrm{a}}{\mathrm{R}}\right)\right]\right\} \frac{P \sqrt{\pi \mathrm{a}}}{2 \mathrm{RB}}
\end{array}
$$

where $2 \mathrm{~S}$ is the specimen $\operatorname{span}(33 \mathrm{~mm}), \mathrm{R}$ is the radius $(25 \mathrm{~mm})$, a is the notch length $(5 \mathrm{~mm}), \mathrm{B}$ is the thickness $(20 \mathrm{~mm}), P$ is the load applied on the specimen, and $Y_{\mathrm{I}}(\mathrm{S} / R)$ is the mode-I geometry factor.

The time to fracture $t_{\mathrm{f}}$ and the displacement of fracture $\delta_{\mathrm{f}}$ are corresponded normally to the peak applied load $P_{\max }$. The fracture toughness $K_{\mathrm{IC}}$ is calculated from Eq. (1) using $P_{\max }$. The mean values of quasistatic fracture toughness for sandstone, gabbro, coarsegrained (CG) marble and fine-grained (FG) marble are $0.93,1.64,0.82$ and $1.5 \mathrm{MPa} \sqrt{\mathrm{m}}$, respectively. For a plane-strain condition, the quasi-static fracture energy $G_{\mathrm{C}}$ is calculated by the well-known Irwin's correlation $G_{\mathrm{C}}=\left(1-v^{2}\right) K_{\mathrm{IC}}^{2} / E$. Experimental data are given in Table 5.

\subsection{Dynamic fracture behaviour}

The dynamic crack initiation toughness $K_{\text {Id }}$ is the critical dynamic SIF at the time to fracture $t_{\mathrm{f}}$, and the dynamic crack growth toughness $K_{\mathrm{ID}}$ is the critical SIF at a specific crack speed $v$, which are given by the following equations (Ravi-Chandar 2004)

$$
\begin{aligned}
& K_{\mathrm{Id}}\left(\dot{K}_{\mathrm{I}}^{\mathrm{dyn}}\right)=K_{\mathrm{I}}^{\mathrm{dyn}}\left(t_{\mathrm{f}}\right) \text { at } t=t_{\mathrm{f}} \\
& K_{\mathrm{ID}}\left(v ; \dot{K}_{\mathrm{I}}^{\mathrm{dyn}}\right)=K_{\mathrm{I}}^{\mathrm{dyn}}(t, v) \text { for } t>t_{\mathrm{f}}
\end{aligned}
$$

where the dynamic loading rate is generally expressed as $\dot{K}_{\mathrm{I}}^{\mathrm{dyn}}=K_{\mathrm{Id}} / t_{\mathrm{f}}$.

To determine the dynamic SIF, the optical methods in combination with high-speed photographs, numerical simulations, strain gauges, quasi-static analysis, and
Table 4 Physical and mechanical properties of rock materials (average value)

${ }^{\text {a }} C_{\mathrm{R}}$ being the Rayleigh wave speed given by, $C_{\mathrm{R}}=$ $(0.862+1.14 v) /(1+v) C_{\mathrm{S}}$

\begin{tabular}{lllllll}
\hline Rock type & $\begin{array}{l}\text { Density } \\
\left(\mathrm{g} / \mathrm{cm}^{3}\right)\end{array}$ & $\begin{array}{l}\rho \text { Elastic } \\
\text { modulus } E \\
(\mathrm{GPa})\end{array}$ & $\begin{array}{l}\text { Poisson's } \\
\text { ratio } v\end{array}$ & $\begin{array}{l}\text { Longitudinal } \\
\text { wave speed } \\
C_{\mathrm{L}}(\mathrm{m} / \mathrm{s})\end{array}$ & $\begin{array}{l}\text { Shear wave } \\
\text { speed } C_{\mathrm{S}} \\
(\mathrm{m} / \mathrm{s})\end{array}$ & $\begin{array}{l}\text { Rayleigh wave } \\
\text { speed } \\
C_{\mathrm{R}}(\mathrm{m} / \mathrm{s})^{\mathrm{a}}\end{array}$ \\
\hline Sandstone & 2.56 & 25 & 0.28 & 3,500 & 1,950 & 1,800 \\
Gabbro & 2.92 & 90 & 0.24 & 6,700 & 3,480 & 3,200 \\
CG Marble & 2.40 & 16 & 0.33 & 2,900 & 1,560 & 1,450 \\
FG Marble & 2.80 & 85 & 0.30 & 6,000 & 2,800 & 2,640 \\
\hline
\end{tabular}


Fig. 2 Experimental techniques (modified after Zhang and Zhao (2013a)), a schematic of the split Hopkinson pressure bar (SHPB) system (not to scale), b close-up view of the partial SHPB bars and a specimen with random speckle patterns (In.

Incident, $R e$. Reflected, $T r$. Transmitted, $H S C$

High-speed camera, $S G_{I n \text {. }}$ : Strain gauge on the incident bar, $S G_{T r}$ : Strain gauge on the transmitted bar, $Z O C$ of interest) Zone of camera, ZOI Zone

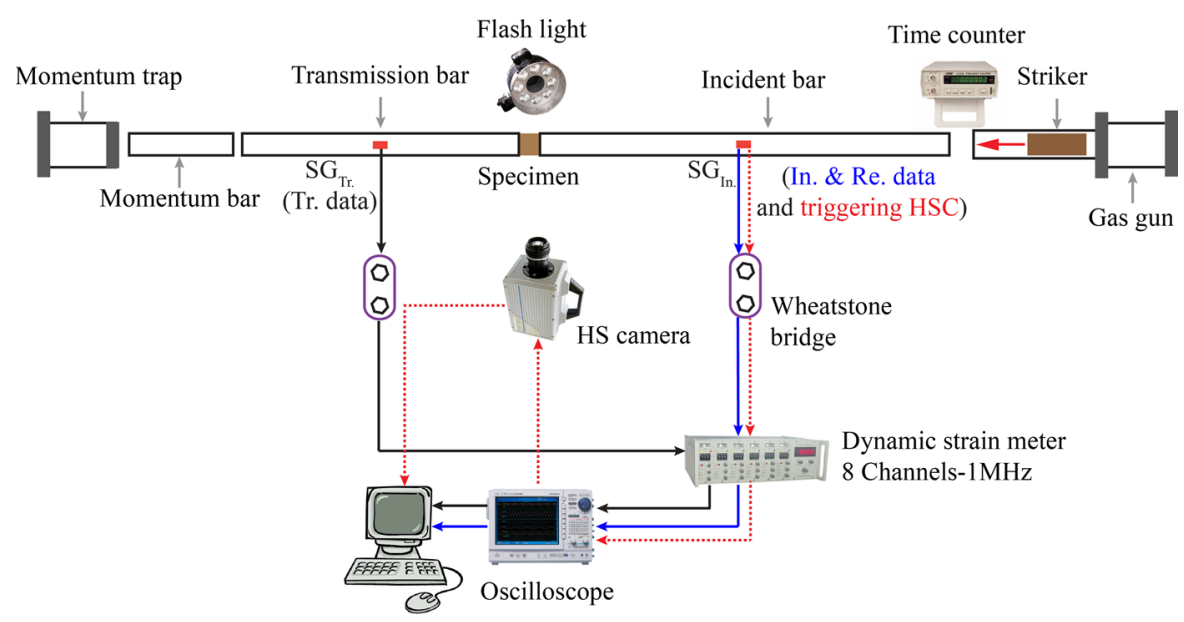

(a)

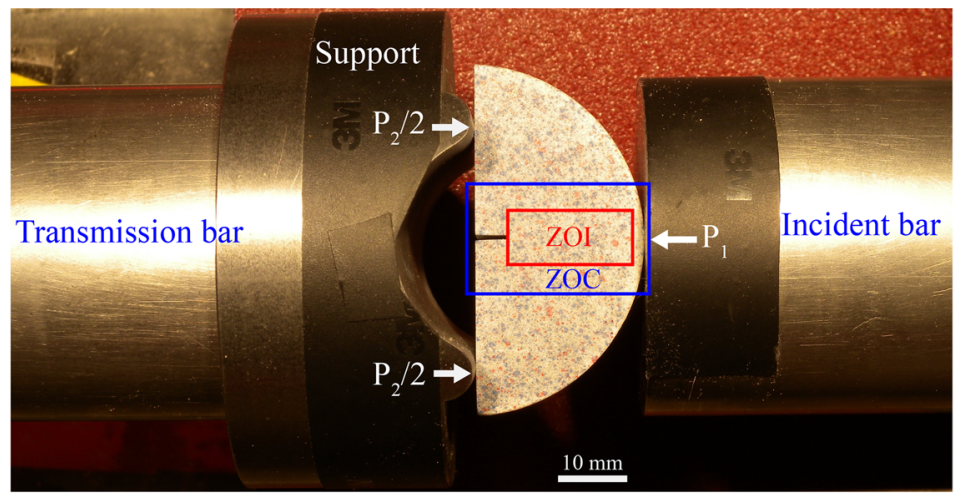

(b)

Table 5 Experimental data of rock materials at the quasi-static loading rate $0.002 \mathrm{~mm} / \mathrm{s}$

\begin{tabular}{lllllll}
\hline Specimen No. & $P_{\max }(\mathrm{N})$ & $t_{\mathrm{f}}(\mathrm{s})$ & $\delta_{\mathrm{f}}(\mathrm{mm})$ & $K_{\mathrm{IC}}(\mathrm{MPa} \sqrt{\mathrm{m}})$ & $v(\mathrm{~mm} / \mathrm{s})$ & $G_{\mathrm{C}}\left(\mathrm{J} / \mathrm{m}^{2}\right)$ \\
\hline S1 & 2,010 & 63 & 0.12 & 0.95 & 230 & 33.3 \\
S2 & 1,960 & 72 & 0.13 & 0.93 & 340 & 31.9 \\
S3 & 1,922 & 92 & 0.14 & 0.91 & 280 & 30.5 \\
G1 & 3,486 & 58 & 0.10 & 1.65 & 584 & 28.5 \\
G2 & 3,562 & 67 & 0.12 & 1.69 & 498 & 29.9 \\
G3 & 3,320 & 65 & 0.12 & 1.57 & 527 & 25.8 \\
CM1 & 1,690 & 90 & 0.16 & 0.80 & 120 & 35.6 \\
CM2 & 1,786 & 82 & 0.15 & 0.85 & 89 & 40.2 \\
CM3 & 1,742 & 79 & 0.15 & 0.81 & 92 & 36.5 \\
FM1 & 3,157 & 64 & 0.12 & 1.50 & 350 & 24.1 \\
FM2 & 3,258 & 69 & 0.11 & 1.54 & 325 & 25.4 \\
FM3 & 3,105 & 75 & 0.13 & 1.47 & 380 & 23.1 \\
\hline
\end{tabular}

the combined methods have been used (see Table 2). We do not discuss these methods in any detail, since the topic is extensively described by Ravi-Chandar (2004) and Jiang and Vecchio (2009).

\subsubsection{Time to fracture}

The time to fracture is defined as the time interval from the beginning of the loading phase to the onset 
of rapid crack propagation. Once the dynamic SIF is determined by an applicable method, the time to fracture is the most important factor (Ravi-Chandar and Knauss 1984a). Electrical resistance strain gauges and optical methods in combination with high-speed photography have been used extensively, as summarized in Table 2. However, it remains challenging to detect precisely the time to fracture, since the fracturing process is in three-dimension (3D) and measurement techniques are only applicable on the surface of opaque specimens. Moreover, the heterogeneities of rocks and the complicated configurations of testing methods to a great extent enhance the challenge, such as the chevron notched crack tip and two crack tips (see Table 2). One could not monitor crack initiation from the chevron notched crack tip using direct measurement techniques, and thus an alternative method (i.e. a strain gauge placed near the crack tip) was used. Although it was assumed that two crack tips initiated at the same time and propagated symmetrically, it was still violated due to the inhomogeneity of rocks and the misalignment of loading.

The time to fracture $t_{\mathrm{f}}$ of rocks was probably first studied by Tang and Xu (1990) using a light passingdetector technique, however only one value of $28 \mu \mathrm{s}$ was given. The values $t_{\mathrm{f}}$ of Fangshan gabbro measured by the Moire method were within the range of 22-60 us (Zhang et al. 1999). The values for Ya'an marble detected by two strain gauges near crack tips were 52-114 $\mu \mathrm{s}$ (HCFBD specimens with the diameter from 42 to $155 \mathrm{~mm}$ ) (Wang et al. 2010) and 61$100 \mu \mathrm{s}$ (CSTBD specimens with the diameter from 50 to $200 \mathrm{~mm}$ ) (Wang et al. 2011). The time determined by strain gauge near the crack tip was regarded as the same as the time of peak-load (Chen et al. 2009; Dai et al. 2010a, b, 2011). However, high-speed photographs of the fracturing process provide a synchronized link between the times of crack initiation and propagation, which have shown that the time to fracture is earlier than that of the peak load (Lambert and Ross 2000; Yu and Zhang 1995; Zhang et al. 1999, 2000; Zhang and Zhao 2013a).

In this study, $t_{\mathrm{f}}$ was measured primarily by highspeed photographs and meantime calibrated by strain gauges or a crack propagation gauge. Figure 3 shows the selected sequence of high-speed photographs from dynamic fracturing tests in each rock type at the striking speed of $3 \mathrm{~m} / \mathrm{s}$, with the time $0 \mu \mathrm{s}$ corresponding to the onset of loading. For example, the first three images in Fig. 3a show the stress wave travels through the speci- men and reaches a state of force equilibrium. The crack ahead of the notch tip becomes visible in the images recorded at the time of $48 \mu \mathrm{s}$, signaling that crack initiation has occurred. It should be noted that the evidence of crack initiation from the images represents the latest time at which initiation may have occurred, since it is possible that the crack may have propagated inside the specimen without having appeared apparently on the surface. Moreover, due to the limitation of the speed and resolution of high-speed cameras, it is still challenging to determine the precise time of crack initiation in quasi-brittle opaque materials. Several interesting characteristics are observed during crack propagation in different rock types: undulated propagation in sandstone; straight cracking in gabbro; unnoticeable ductile fracturing in CG marble; individual white belt occurs prior to the initiation of an observable crack in FG marble; and many small particles are obviously seen in sandstone, FG marble and CG marble after crack completely split the specimen. Except the straight cracking, the others would to some extent limit the crack speed. The experimental data on the time to fracture are presented together with the results of dynamic crack initiation toughness, as well as tabulated in Table 8 in "Appendix".

\subsubsection{Dynamic crack initiation toughness}

It has been generally recognized that the fracture toughness of rock materials increases with increasing loading rate, though the normalized fracture toughness (i.e. the ratio of dynamic fracture toughness to quasi-static fracture toughness, $K_{\mathrm{Id}} / K_{\mathrm{IC}}$ ) is different from unity. Most studies show that the dynamic fracture toughness is several times higher than the corresponding quasistatic value (Zhang and Zhao 2014), whereas Zhang et al. $(1999,2000)$ presented the highest values of $K_{\text {Id }} / K_{\text {IC }}$ for Fangshan gabbro and marble are about 20 and 40, respectively. The distinct differences of conclusions are primarily caused by rock types, experimental techniques, and the methods for the determination of dynamic SIF and the time to fracture.

It has been reported that the specimen is in a state of force equilibrium through the time to fracture $t_{\mathrm{f}}$ (Chen et al. 2009; Zhang and Zhao 2013a; Zhou et al. 2012), and the dynamic crack initiation toughness $K_{\text {Id }}$ is thus determined by Eq. 1 using the mean force applied on the specimen and $t_{\mathrm{f}}$. The experimental data of $K_{\mathrm{Id}} / K_{\mathrm{IC}}$ and $t_{\mathrm{f}}$ are presented in Fig. 4. Liu et al. (1998) derived a tran- 
(a)
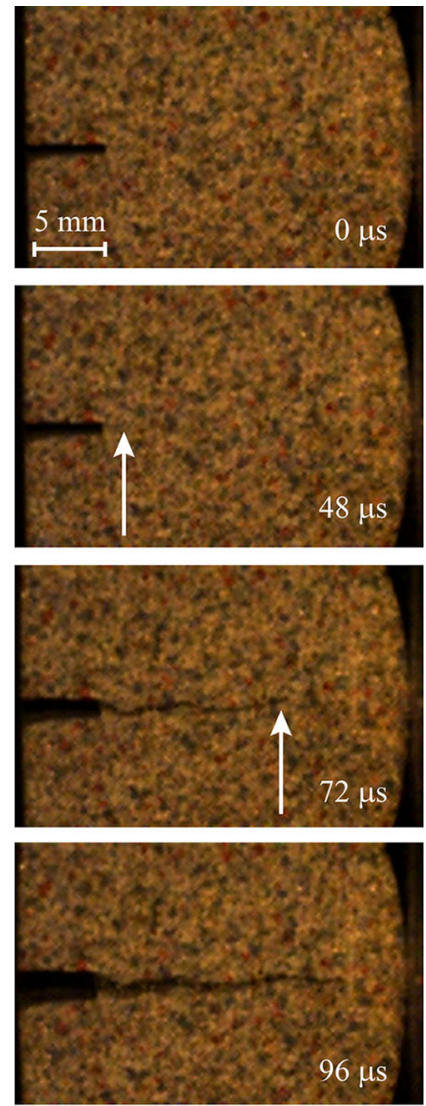

(b)
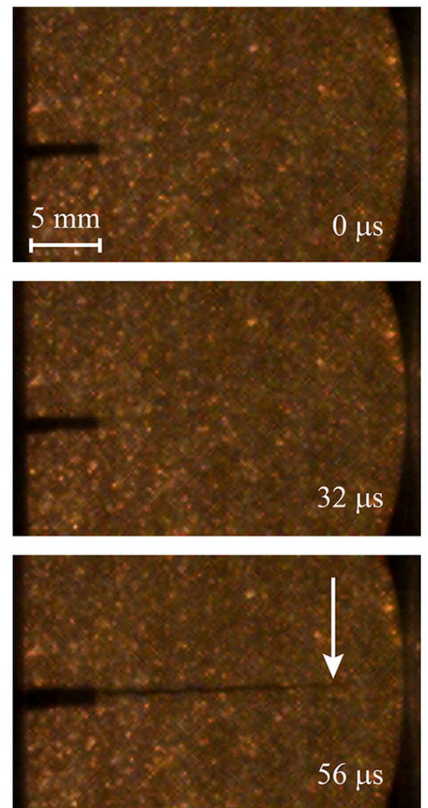

Fig. 3 High-speed photographs showing dynamic fracturing process of, a sandstone (S5-SG4), b gabbro (G6-CPG), c coarsegrained marble (CM4-SG2), d fine-grained marble (FM6-CPG),
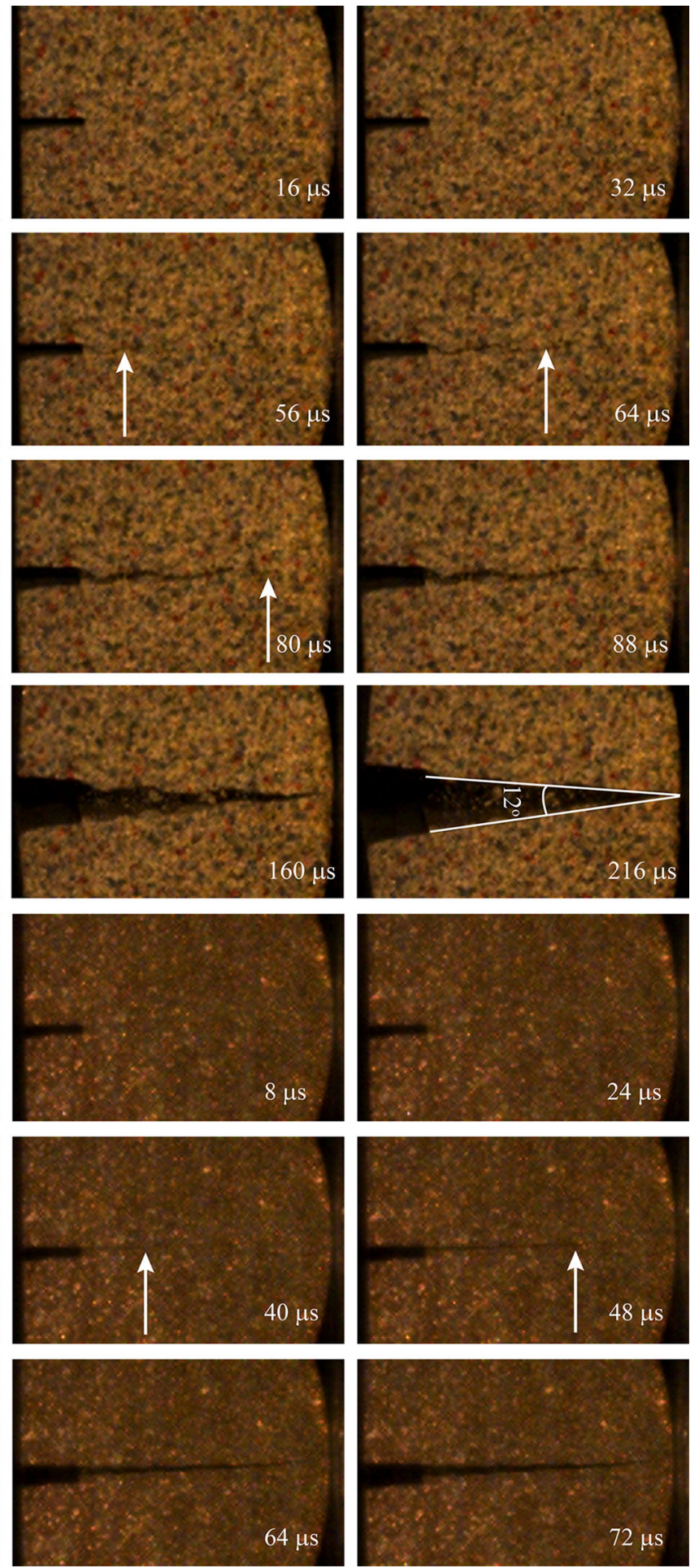

at the striking speed of $3 \mathrm{~m} / \mathrm{s}$ (The position of observable crack tip was denoted as a solid arrow) 
Fig. 3 continued

(c)
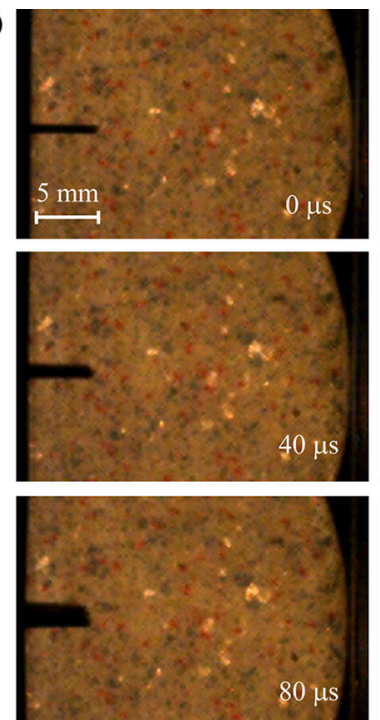

$80 \mu \mathrm{s}$

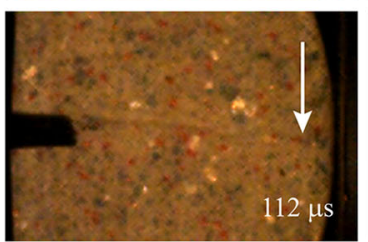

(d)
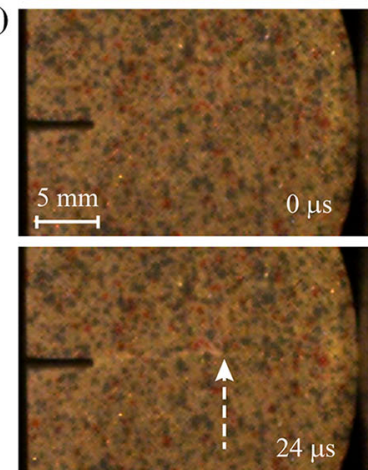

$24 \mu \mathrm{s}$

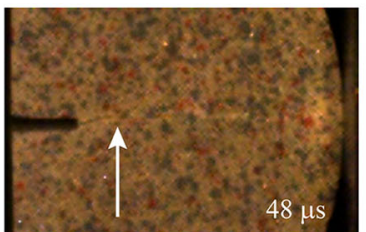

$48 \mu \mathrm{s}$

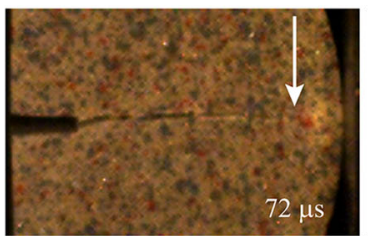

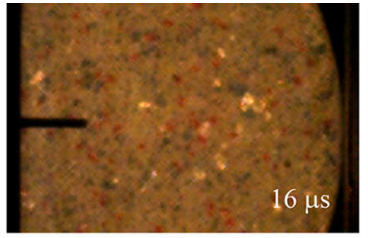
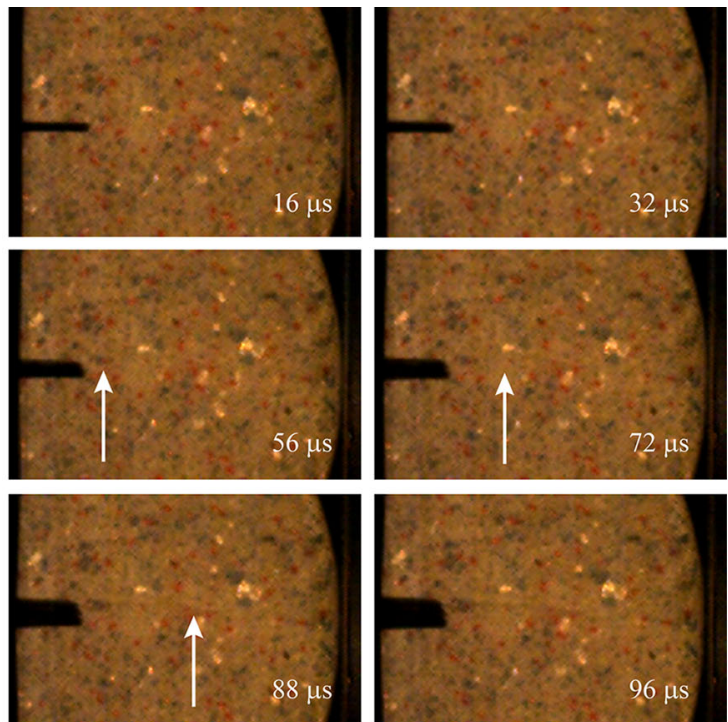

$216 \mu \mathrm{s}$

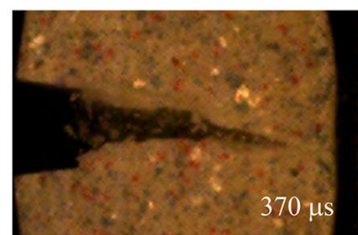

$8 \mu \mathrm{s}$
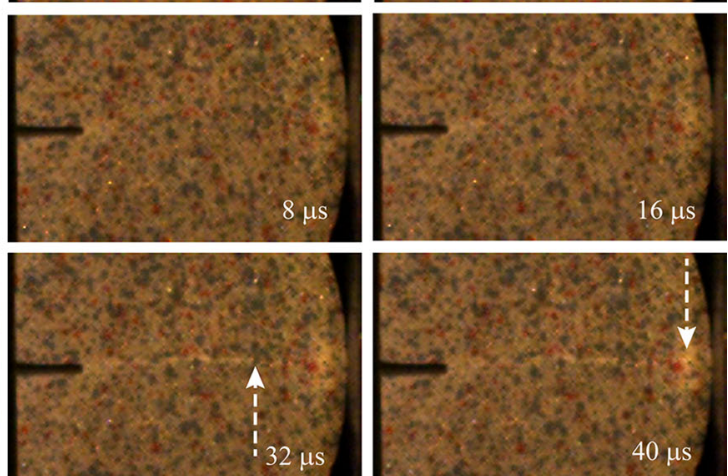

$56 \mu \mathrm{s}$
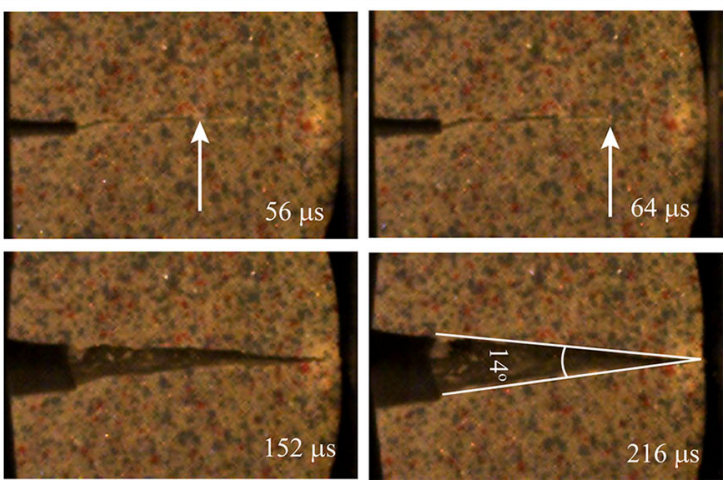

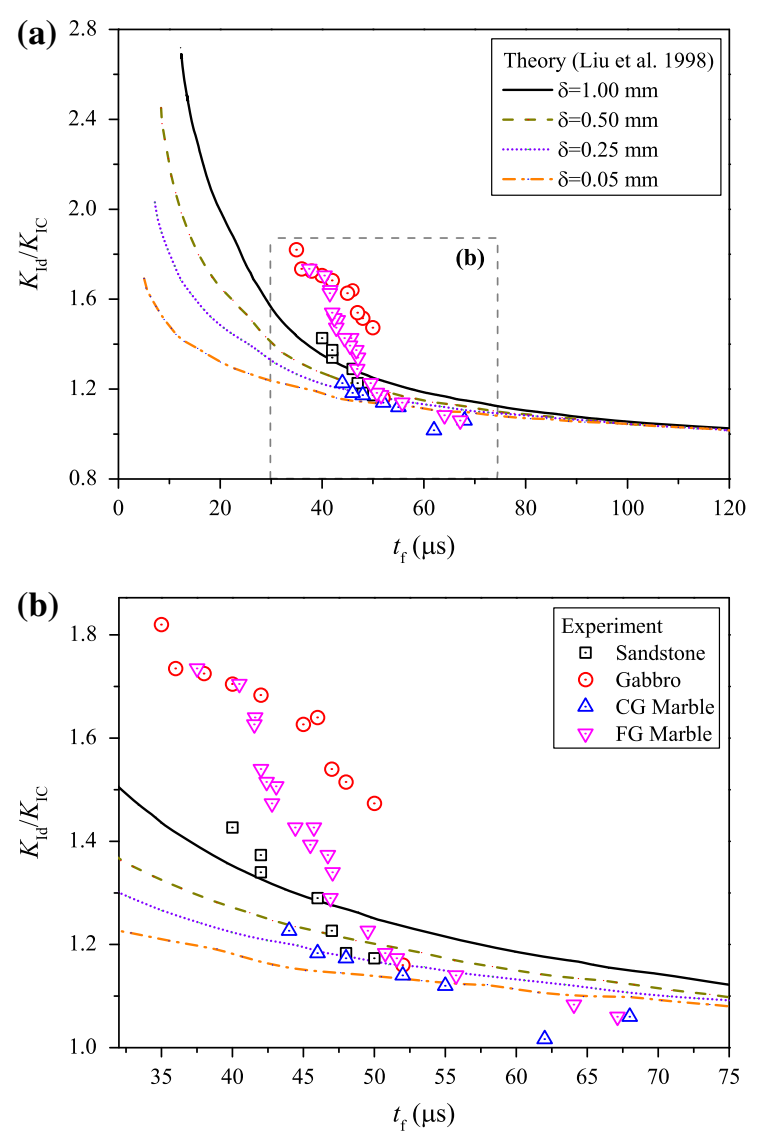

Fig. 4 Normalized dynamic crack initiation toughness $K_{\text {Id }} / K_{\text {IC }}$ and time to fracture $t_{\mathrm{f}}$ of, $\mathbf{a}$ an analytical solution with different critical distance $\delta$ (Liu et al. 1998) and experimental data, b the magnified view

sient elastodynamic solution from inertial constraints on the development of the stress field near the crack tip and postulated that crack initiation is regarded in terms of activating a flaw at some distance from the tip. Thus, the observed increase in crack initiation toughness is attributed to the time required to reach a critical stress state ahead of the crack tip over a critical distance. The similar investigations on the effect of loading rate were conducted by Kalthoff (1986) who predicted the existence of an incubation time for crack initiation and by Kim and Chao (2007) who proposed a crack-tip constraint model. Liu et al. (1998) analytically modelled the experimental measurements of Ravi-Chandar and Knauss (1984a) for Homalite-100 material by estimating the critical SIF on the basis of different critical distance $\delta$. Both the experimental data and the analytical prediction (Liu et al. 1998) are presented in Fig. 4, which reveals good agreement in general trend.

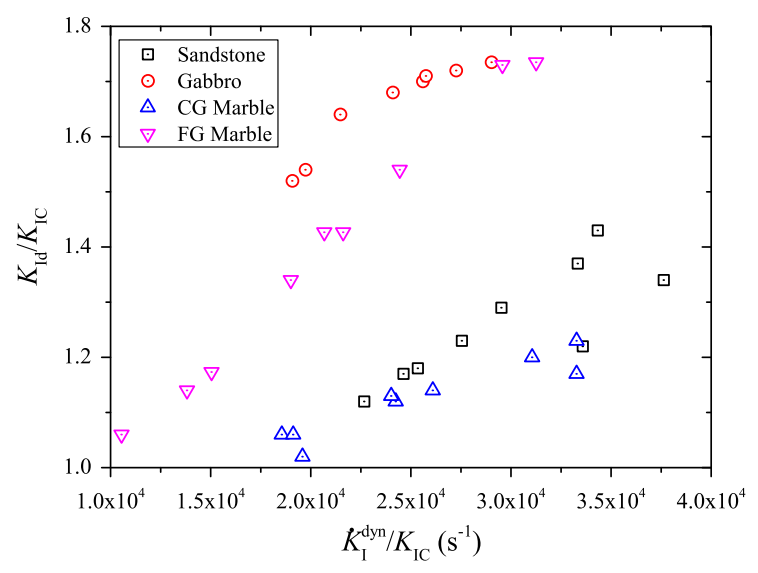

Fig. 5 Normalized dynamic crack initiation toughness $K_{\mathrm{Id}} / K_{\mathrm{IC}}$ as a function of normalized loading rate $\dot{K}_{\mathrm{I}}^{\text {dyn }} / K_{\mathrm{IC}}$ for selected rock materials

Some of the differences are explained as being caused probably by the indirect tension configuration of the NSCB method and the inhomogeneity of rock materials, since the analytical solutions are based on a single edge cracked plate of the homogeneous Homalite-100 material with uniform pressure loading applied on the crack surface. Another possible reason is due to the size of the fracture process zone (FPZ) located at the crack tip that will change with the loading rate; however, the available experimental data on loading rate dependence of the FPZ size of rock-like materials are varied and contradictory (Du et al. 1992; Zhang et al. 2010).

It can also be seen from Fig. 4 that the values of $K_{\text {Id }} / K_{\text {IC }}$ in gabbro and FG marble are apparently higher than those in sandstone and CG marble, which are governed primarily by the time of stress wave required to travel through the specimen, in other words by the longitudinal wave speed of the rock (i.e., the higher the speed is, the shorter the time is required to reach force equilibrium.), and by the interactions of multiple microcracks with the main crack tip to some extent delay the onset of crack initiation. Figure 5 shows the normalized dynamic crack initiation toughness $K_{\mathrm{Id}} / K_{\mathrm{IC}}$ as a function of normalized loading rates $\dot{K}_{\mathrm{I}}^{\text {dyn }} / K_{\mathrm{IC}}$. The general trend of $K_{\mathrm{Id}} / K_{\mathrm{IC}}$ for the four rocks increases almost linearly with the increased of $\dot{K}_{\mathrm{I}}^{\text {dyn }} / K_{\text {IC }}$ in the range of $1 \times 10^{4}-4 \times 10^{4} \mathrm{~s}^{-1}$. The values $K_{\mathrm{Id}} / K_{\mathrm{IC}}$ of gabbro and FG marble are apparently higher than those of sandstone and CG marble, and the differences are governed primarily by the time 
of stress wave required to travel through the specimen as discussed previously.

\subsubsection{Crack speed}

It has been found that, once the limit of crack speed is reached, the propagating crack forms additional multiple cracks at an angle to the original path (Ravi-Chandar and Knauss 1984c). The phenomena of macrobranches have been observed in nominally brittle materials and the limiting crack speeds $v_{\text {lim }}$ are in the range of 0.33 and $0.66 C_{\mathrm{R}}$ (Rayleigh wave speed) [(Table 11.1 in Ravi-Chandar (2004)].

For brittle heterogeneous materials in particular rock-like materials, there have been, however, very few investigations, probably due to technical difficulties associated with experiments. Lagunov and Mambetov (1965) performed explosion tests on 12 different types of rock. The measured crack speeds were between 1,000 and $2,700 \mathrm{~m} / \mathrm{s}$ and the values of $v / C_{\mathrm{L}}$ were in the range from 0.34 to 0.51 (Lagunov and Mambetov 1965). However, the results were suspicious since the maximum crack speed $v_{\max }$ might be faster than the Rayleigh wave speed $C_{\mathrm{R}}$. The available values $v_{\text {lim }}$ of limestone (Bertram and Kalthoff 2003) and norite rock (Bieniawski 1968) under projectile impacts are about 2,000 and $1,875 \mathrm{~m} / \mathrm{s}$, and the values of $v_{\text {lim }}$ are $0.71 C_{\mathrm{R}}$ and $0.68 C_{\mathrm{R}}$, respectively. The crack speeds and associated measurement techniques in the literature are summarized in Table 6. For the comparison with $v_{\lim }$ in nominally brittle materials, the ratio $v_{\max } / C_{\mathrm{R}}$ is used, lying in the range from 0.2 to 0.71 , except those obtained from the combined method with a strain gauge and numerical modelling (Dai et al.2010a, 2011).

As reported by Zhang and Zhao (2013a), the crack speeds exhibit an initial increase followed by a levelling off. The crack speeds at the constant stage are presented in Table 6 and also in Table 8 in Appendix. The ranges of crack speed in sandstone, gabbro, CG marble and FG marble are 300-650, 430-1,120, 280-480, and $320-1,000 \mathrm{~m} / \mathrm{s}$, respectively, and the corresponding ratio $v_{\max } / C_{\mathrm{R}}$ are $0.36,0.35,0.33$, and 0.38 . It should be mentioned that when the striking speed is higher than $5 \mathrm{~m} / \mathrm{s}$, the experimental data are no longer valid, since the position of crack initiation is from the bar/specimen contact points rather than the notch tip. The phenomena of macrobranches are not observed during tests, perhaps due to the small size of specimen and the indirect tension testing method.

\subsubsection{Dynamic fracture energy}

It is reported that the effective energy applied for rock breakage and fragmentation in mining excavation is much smaller than the total input energy (Zhang et al. 2000). To increase the efficiency, it is imperative to investigate quantitatively the energy partition in dynamic fracture. The determination of dynamic fracture energy is challenging at high loading rates due to the limitation of measurement techniques. Some attempts have been made in uniaxial compression ( $\mathrm{Li}$ et al. 2005; Lundberg 1976), fracture toughness (Chen et al. 2009; Zhang et al. 2000) and spalling (Schuler et al. 2006) tests. In the SHPB test, the energies of the incident wave $W_{\mathrm{In}}$, the reflected wave $W_{\mathrm{Re}}$, and the transmitted wave $W_{\text {Tr. }}$ are expressed respectively as (Lundberg 1976),

$$
\begin{aligned}
& W_{\text {In. }}=\frac{A_{\mathrm{B}} C_{\mathrm{B}}}{E_{\mathrm{B}}} \int \sigma_{\text {In. } .}(t)^{2} \mathrm{~d} t, \\
& W_{\text {Re. }}=\frac{A_{\mathrm{B}} C_{\mathrm{B}}}{E_{\mathrm{B}}} \int \sigma_{\text {Re. }}(t)^{2} \mathrm{~d} t, \\
& W_{\text {Tr. }}=\frac{A_{\mathrm{B}} C_{\mathrm{B}}}{E_{\mathrm{B}}} \int \sigma_{\operatorname{Tr} .}(t)^{2} \mathrm{~d} t
\end{aligned}
$$

where $A_{\mathrm{B}}$ is the cross-sectional area, $C_{\mathrm{B}}$ is the longitudinal wave speed, and $E_{\mathrm{B}}$ is the Young's modulus of the bars, and $\sigma$ is the stress measured by strain gauges on the bars (The subscripts In., Re. and Tr. correspond to the incident, reflected and transmitted pulse, respectively.).

The following factors should be carefully considered: the forces on both sides of the specimen are nonequilibrium during wave propagation; the effect of multiple pulse waves needs to be eliminated; and the friction between the specimen and the bars should be small enough. In the present study, the single pulse wave is achieved by means of a longer length of the incident bar and a momentum trap. There are three-point contacts in the NSCB method to transfer dynamic loads: one contact is between the incident bar and the top point of the specimen, and the other two contacts are formed by two supporting pins and the specimen, as shown in Fig. 2b. During the test, the notch of the specimen opens up and meantime results in frictional forces by the pins to resist separation. Lubricants are used on the bar/specimen interfaces to reduce the friction effect. Xia et al. (2013) also pointed out that the coefficient of friction of the NSCB method was about 0.02 in a well- 
Table 6 Summary of crack speeds in rock-like materials under dynamic loads

\begin{tabular}{|c|c|c|c|c|c|c|c|}
\hline $\begin{array}{l}\text { Loading } \\
\text { technique }\end{array}$ & Testing method & Rock type & $\begin{array}{l}\text { Measurement } \\
\text { technique }\end{array}$ & $v(\mathrm{~m} / \mathrm{s})$ & $C_{\mathrm{R}}(\mathrm{m} / \mathrm{s})$ & $\frac{v_{\max }}{C_{\mathrm{R}}}$ & References \\
\hline \multirow[t]{7}{*}{$\begin{array}{l}\text { Drop } \\
\text { weight } \\
\text { machine }\end{array}$} & \multirow[t]{7}{*}{ SENB } & Concrete & $\begin{array}{l}\text { Electrical } \\
\text { circuit }\end{array}$ & $500-700$ & 2,115 & 0.30 & $\begin{array}{l}\text { Curbach } \\
\text { and Eibl } \\
\text { (1990) }\end{array}$ \\
\hline & & Rock & Caustic & 400 & & & $\begin{array}{l}\text { Yang et al. } \\
\text { (2009) }\end{array}$ \\
\hline & & Limestone & $\begin{array}{l}\text { HS- } \\
\text { camera }\end{array}$ & 1,332 & 2,773 & 0.48 & $\begin{array}{l}\text { Liu et al. } \\
\text { (2010) }\end{array}$ \\
\hline & & Marble & & 1,218 & 2,670 & 0.46 & \\
\hline & & Gneiss & & 1,045 & 2,516 & 0.42 & \\
\hline & & Concrete & $\begin{array}{l}\text { Strain } \\
\text { gauge }\end{array}$ & $208-417$ & 2,120 & 0.20 & $\begin{array}{l}\text { Zhang et al. } \\
\text { (2010) }\end{array}$ \\
\hline & & Coal & $\begin{array}{l}\text { HS- } \\
\text { camera }\end{array}$ & $234-325$ & 1,350 & 0.24 & $\begin{array}{l}\text { Zhao et al. } \\
\text { (2013) }\end{array}$ \\
\hline \multirow{9}{*}{$\begin{array}{l}\text { Split Hop- } \\
\text { kinson } \\
\text { bar }\end{array}$} & NSCB & Granite & $\begin{array}{l}\text { Crack } \\
\text { gauge }\end{array}$ & $300-850$ & $2,300-2,500^{\mathrm{a}}$ & 0.37 & $\begin{array}{l}\text { Chen et al. } \\
\text { (2009) }\end{array}$ \\
\hline & CCNBD & & $\begin{array}{l}\mathrm{SG}+ \\
\text { FEM }\end{array}$ & $80^{\mathrm{b}} ; 150^{\mathrm{c}}$ & & 0.065 & $\begin{array}{l}\text { Dai et al. } \\
(2010 a)\end{array}$ \\
\hline & CCNSCB & & $\begin{array}{l}\mathrm{SG}+ \\
\text { FEM }\end{array}$ & $65-99^{\mathrm{b}} ; 135-176^{\mathrm{c}}$ & & 0.07 & $\begin{array}{c}\text { Dai et al. } \\
(2011)\end{array}$ \\
\hline & $\mathrm{UC}$ & Ceramic & $\begin{array}{l}\text { HS- } \\
\text { images }\end{array}$ & 1,500 & 5,820 & 0.25 & $\begin{array}{l}\text { Hu et al. } \\
(2011)\end{array}$ \\
\hline & RST & Concrete & $\begin{array}{l}\text { Crack } \\
\text { gauge + } \\
\text { HS-DIC }\end{array}$ & 1,300 & 2,300 & 0.57 & $\begin{array}{l}\text { Forquin } \\
\text { (2012) }\end{array}$ \\
\hline & \multirow[t]{4}{*}{ NSCB } & Sandstone & $\begin{array}{l}\text { Electrical } \\
\text { circuit + } \\
\text { SG + } \\
\text { HS- } \\
\text { camera }\end{array}$ & $300-650$ & 1,800 & 0.36 & This paper \\
\hline & & Gabbro & & $430-1,120$ & 3,200 & 0.35 & \\
\hline & & CG Marble & & $280-480$ & 1,450 & 0.33 & \\
\hline & & FG Marble & & $320-1,000$ & 2,640 & 0.38 & \\
\hline $\begin{array}{l}\text { Projectile } \\
\text { impact } \\
\text { technique }\end{array}$ & LECEI $^{\mathrm{d}}$ & Limestone & $\begin{array}{l}\text { SGs + } \\
\text { HS- } \\
\text { camera }\end{array}$ & 2,000 & $2,820^{\mathrm{e}}$ & 0.71 & $\begin{array}{l}\text { Bertram and } \\
\text { Kalthoff } \\
(2003)\end{array}$ \\
\hline
\end{tabular}

${ }^{\text {a }}$ Shear wave speed $C_{\mathrm{S}}(2,550-2,740 \mathrm{~m} / \mathrm{s})$ from (Nasseri and Mohanty 2008) and Poisson's ratio $v(0.21)$ from (Dai et al. 2011)

b Stable crack speed

${ }^{\mathrm{c}}$ Unstable crack speed

${ }^{\mathrm{d}}$ LECEI: Loading edge cracks by edge impact

${ }^{\mathrm{e}}$ Shear wave speed $C_{\mathrm{S}}(3,050 \mathrm{~m} / \mathrm{s})$ and Poisson's ratio $v(0.29)$ from (Schubnel et al. 2005)

lubricated SHPB test. The friction can be ignored, and thus the energy absorbed by the specimen $W_{\mathrm{S}}$ is given by

$$
W_{\mathrm{S}}=W_{\text {In. }}-W_{\text {Re. }}-W_{\text {Tr. }}
$$

Continuing on Figs. $3 \mathrm{~b}$ and $6 \mathrm{a}$ show high-speed photographs of the gabbro until the NSCB specimen is split into two almost equal fragments, and each flying fragment has a combined rotational and translational motion. The translational velocity $v_{\mathrm{T}}$ is calculated by 
(a)
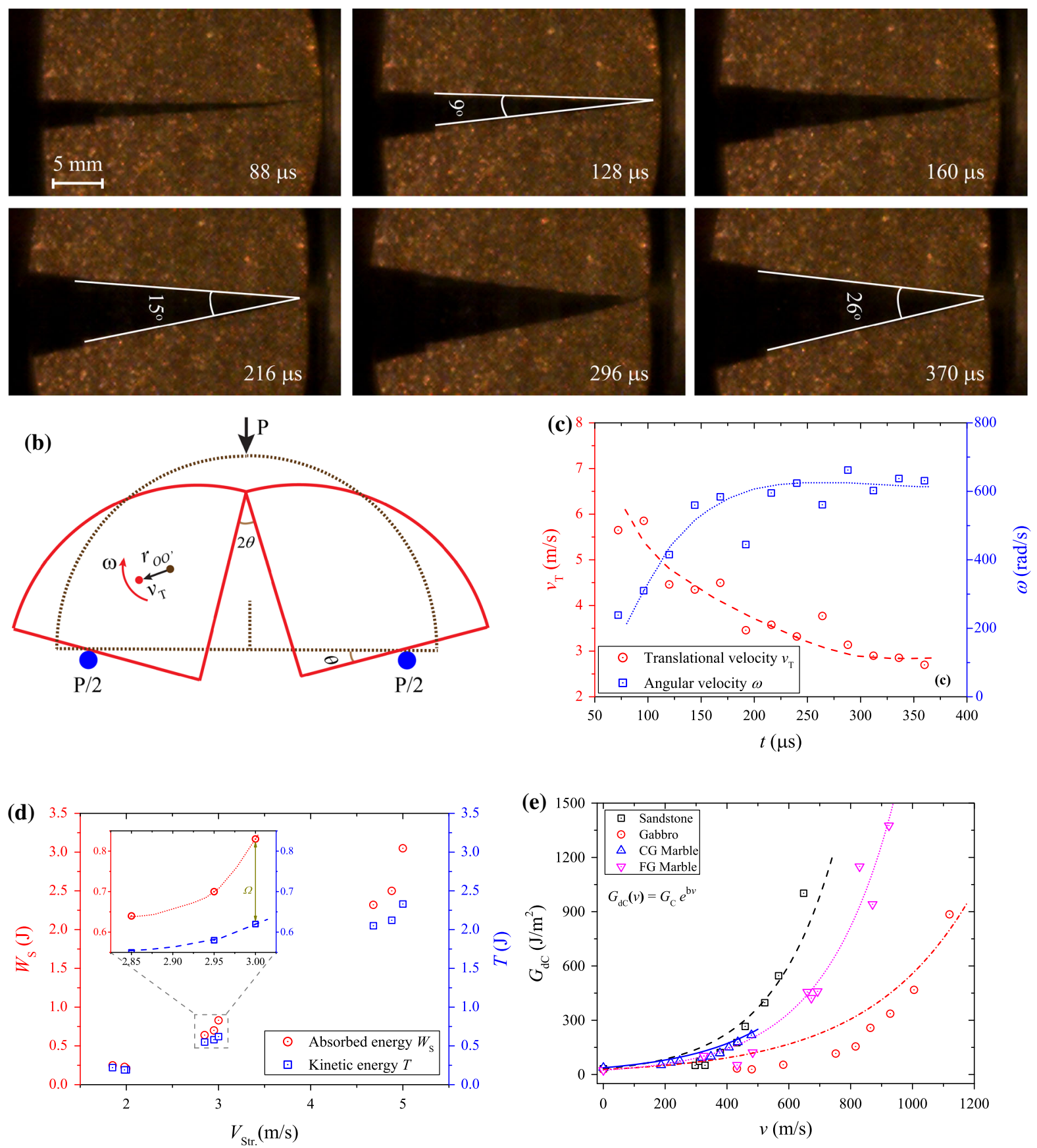

Fig. 6 a High-speed photographs of the movement of the flying fragments after impact (continuing on Fig. 3b), b schematic of the fracturing specimen ( $O$ is the center of mass, $r_{O O^{\prime}}$ is the distance of translational movement), $\mathbf{c}$ translational and angular

velocity of the flying fragments, $\mathbf{d}$ comparison of kinetic energy of flying fragments with absorbed energy of gabbro, e dynamic fracture energy as a function of crack speed

the subsequent translational movement of the centre of mass $r_{O O^{\prime}}$ and the time from the corresponding pho-

tographs; and the angular velocity $\omega$ is estimated by the rotational angle $\theta$ with respect to relative time, as 
defined schematically in Fig. 6b. The local coordinates of the centre of mass and the rotational angles of the fragments can be quantitatively determined by the relative photographs at each time step. At the initial stage, $v_{\mathrm{T}}$ shows a decreasing trend, but $\omega$ increases with the increase of time, as shown in Fig. 6c, which indicate obviously that the increase of $\omega$ is on the expense of the reduction of $v_{\mathrm{T}}$. Then both of velocities become constant, which reveals that there is no change in the total kinetic energy. From the measured velocity of one fragment at each time step, the kinetic energy for rotation, $T_{\text {Rot. }}=\frac{1}{2} I \omega^{2}$, and for translation, $T_{\text {Tra. }}=\frac{1}{2} m v_{\mathrm{T}}^{2}$ can be determined. The total kinetic energy $T$ of two fragments is given by

$T=2\left(T_{\text {Tra. }}+T_{\text {Rot. }}\right)=m v_{\mathrm{T}}^{2}+I \omega^{2}$

where $m$ is the mass of one fragment, and $I=$ $\frac{R^{2}}{36 \pi^{2}}\left(9 \pi^{2}+18 \pi-128\right) m$ is the moment of inertia around the axis of rotation.

Figure $6 \mathrm{~d}$ shows the results of the total kinetic energy $T$ and the absorbed energy $W_{\mathrm{S}}$ under three striking impact speeds $V_{\text {Str. }}$. The absorbed energy $W_{\mathrm{S}}$ is primarily partitioned into three parts: the total kinetic energy $T$ of the flying fragments; the dissipated energy $\Omega$ that is associated with fracture surface and micro-cracks; and other energy, such as thermal energy. The loading rate in the present study is not very high, and thus other energy is assumed to be very small and negligible for the results. Therefore, the dissipated energy is obtained by $\Omega=W_{\mathrm{S}}-T$ (see the top left inset in Fig. 6d), and the dynamic fracture energy (dissipated per unit area $\partial A$ created) is written as $G_{\mathrm{dC}}=\partial \Omega / \partial A$. To simplify, the experimental measurable quantity $A_{\mathrm{S}}$ (i.e. the actual area of the fractured surface), and the calculated $\Omega$ are used to estimate the average fracture energy. The measurement of surface topography is conducted by a 3D laser profilometry and the approximate area of $A_{\mathrm{S}}$ is estimated using the triangular prism surface area method (Clarke 1986). As shown in Fig. 6d, the values of the absorbed energy $W_{\mathrm{S}}$ are apparently higher than the total kinetic energy $T$ with increase of the impact speed $V_{\text {Str. }}$. With the assumption of the conservation of energy, the dissipated energy for creating fracture surface and micro-cracks is increased with the range of impact speeds. A fundamental aim of the study of a stationary crack under dynamic loading is examine the energy balance equation and the crack-tip equa- tion of motion (Ravi-Chandar 2004). Figure 6e shows the dynamic fracture energy approaches to a low level when the crack speed $v$ is small and increases rapidly with the increase of $v$, which reveals that rock materials have the property of the crack speed-toughening. A phenomenological rate-dependent fracture energy that is a function of crack speed $G_{\mathrm{dC}}(v)$ is broadly accepted Dally et al. (1985). For a mode I crack, when the crack speed $v$ approaches to Rayleigh wave speed $C_{\mathrm{R}}$, the dynamic fracture energy becomes very large $\lim _{v \rightarrow C_{\mathrm{R}}} G_{\mathrm{dC}}(v)=\infty$. The observed limiting speeds $v_{\text {lim }}$ are significantly smaller than $C_{\mathrm{R}}$ in nominally brittle materials (Ravi-Chandar 2004). As discussed previously, there is still lacking of limiting speeds $v_{\text {lim }}$ for rock-like materials, and the maximum crack speeds $v_{\max }=(0.2-0.71) C_{\mathrm{R}}$ are in a wide range. Therefore, a semi-empirical rate-dependent model is proposed for the simulation of crack propagation in rock materials using the ratio of a theoretical characteristic velocity $v_{0}$ (assuming as a material constant) to $C_{\mathrm{R}}$. The relationship between $G_{\mathrm{dC}}(v)$ and $v$ plotted in Fig. 6e is fitted by a two-parameters expression as follow

$G_{\mathrm{dC}}(v)=G_{\mathrm{C}} e^{b v}$

where $G_{\mathrm{C}}$ is quasi-static fracture energy, and $b$ is a material constant, $b=0.01 v_{0} / C_{\mathrm{R}}$. The values of $b$ for sandstone, gabbro, coarse-grained marble and finegrained marble are 0.0048, 0.003, 0.0038 and 0.004, respectively. Thus, the corresponding theoretical characteristic velocities $v_{0}$ are $864,960,551$, and $1,056 \mathrm{~m} / \mathrm{s}$, which are nearly as the same as the measured maximum crack speeds $v_{\max }$ (refer to Table 6 for details).

\subsubsection{Dynamic crack growth toughness}

Pioneering research on dynamic crack growth toughness $K_{\text {ID }}$ was performed on Solnhofen limestone using a projectile impact technique and an on-specimen strain gauge (Bertram and Kalthoff 2003). We attempted to use the method of strain gauge to determine the dynamic SIF, but the results were hardly repeatable, perhaps due to the heterogeneity of rocks. In the SHPB test, the forces on both sides of a specimen are nonequilibrium after the time to fracture (Foster et al. 2011; Zhang and Zhao 2013a), and the dynamic SIF becomes a function of crack speed. Due to the limitation of the speed and resolution of high-speed camera, it is still challenging to measure the dynamic displacement 


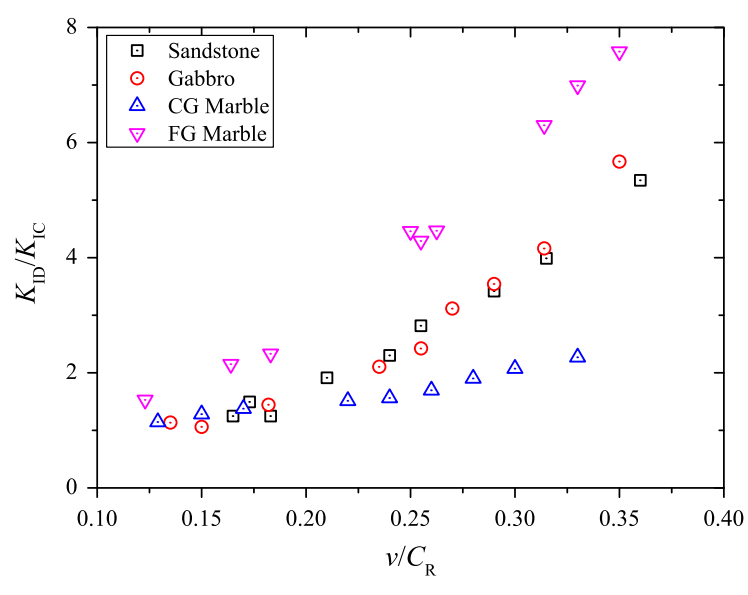

Fig. 7 Normalized dynamic crack growth toughness $K_{\text {ID }} / K_{\text {IC }}$ as a function of normalized crack speed $v / C_{\mathrm{R}}$ of rock materials

fields in quasi-brittle opaque materials. Thus, indirect methods were applied to estimate $K_{\mathrm{ID}}$. For example, Chen et al. (2009) calculated the $G_{C}$ by the results of a laser gap gauge and high-speed photography, and determined the $K_{\mathrm{ID}}$ on the basis of well-known Irwin's equation $K_{\mathrm{IC}}=\sqrt{G_{\mathrm{C}} E /\left(1-v^{2}\right)}$. However, it should be noted that the above equation is only applicable for the quasi-static loading, however, when a crack propagates dynamically, the dynamic energy release rate $G_{\mathrm{d}}(t, v)$ is related to the dynamic SIF $K_{\mathrm{I}}^{\mathrm{dyn}}(t, v)$ (Ravi-Chandar 2004),

$G_{\mathrm{d}}(t, v)=A_{\mathrm{I}}(v) \frac{1-v^{2}}{E}\left[K_{\mathrm{I}}^{\mathrm{dyn}}(t, v)\right]^{2}$

Thus, $K_{\mathrm{ID}}$ at a specific crack speed is derived by the critical $G_{\mathrm{dC}}$ via

$K_{\mathrm{ID}}=\sqrt{\frac{1}{A_{\mathrm{I}}(v)} \frac{G_{\mathrm{dC}} E}{1-v^{2}}}$

where $A_{\mathrm{I}}(v)=\frac{v^{2} \alpha_{\mathrm{d}}}{(1-v) C_{\mathrm{S}}^{2} R(v)}, \alpha_{\mathrm{d}}=\sqrt{1-\frac{v^{2}}{C_{\mathrm{L}}^{2}}}, \alpha_{\mathrm{s}}=$ $\sqrt{1-\frac{v^{2}}{C_{\mathrm{S}}^{2}}}, R(v)=4 \alpha_{\mathrm{d}} \alpha_{\mathrm{s}}-\left(1+\alpha_{\mathrm{s}}^{2}\right)^{2}$

Figure 7 shows that the normalized value of $K_{\mathrm{ID}} / K_{\mathrm{IC}}$ increases with the increase of $v / C_{\mathrm{R}}$. It is interesting to note that the rate-sensitivity of growth toughness is more evident than that of initiation toughness. The values of $K_{\mathrm{ID}} / K_{\mathrm{IC}}$ in CG marble are apparently lower than those in other three rocks, which depend on the dissipated energy to create the crack surface area.

\section{Characterizations of failure mechanisms}

The macroscopic and microscopic aspects of fracture behaviour are closely linked, and thus it is essential to interpret the macroscopic behaviour by identification of failure mechanisms on the microscopic scale (RaviChandar and Knauss 1984b). It has been well recognized that fracture surface topography reveals inherent details associated energy dissipation mechanisms that govern the fracturing process (Field 1971; RaviChandar 2004). Ravi-Chandar and Yang (1997) proposed that the increase of crack initiation toughness in polymers is caused by multiple microcracks formed around the crack tip, whose interaction with the main crack tip delays the onset of crack initiation, thereby leading to an increase of the measured crack initiation toughness. Zhou et al. (2005) also explained that the notable increase of energy dissipation in polymethylmethacrylate with increasing crack speed is governed by the interaction of multiple microcracks around the crack tip zone. Multiple microcracks have been formed in the high-stress region (ahead of the main crack tip) and crack extension has occurred by the crack progressively linking up with microcracks, which has been recognized as one of the most significant toughening mechanisms in rock-like materials (Atkinson 1987; Rose 1986).

Substantial efforts have also been devoted to performing quantitative micromeasurements on fracture surface, and it is clear that surface roughness in many brittle and quasi-brittle materials exhibit self-affine properties at least over a given range of length scales (e.g., the fracture process zone) under quasi-static loading conditions [see Table 1 in Ref. (Bonamy and Bouchaud 2011) for details]. The effects of crack propagation are of great importance in fractographic studies since fracture surfaces are only produced by moving cracks, which has been well studied in amorphous materials (Ravi-Chandar 2004). However, for rock materials, there is no universal rule for the relationship between the surface roughness and loading rate or crack speed (Xie and Sanderson 1995). For example, Fujimura et al. (1986) pointed out that the fractal dimension of basalt and dunite produced by impact loading was apparently lower than that by quasi-static 
Table 7 Summary of fractal dimension or roughness exponent of rocks under quasi-static and dynamic loading conditions

\begin{tabular}{|c|c|c|c|c|c|c|c|c|}
\hline $\begin{array}{l}\text { Loading } \\
\text { technique }^{\mathrm{a}}\end{array}$ & $\begin{array}{l}\text { Testing } \\
\text { method }\end{array}$ & Rock type & $\begin{array}{l}\text { Measurement } \\
\text { technique }\end{array}$ & Resolution & $\begin{array}{l}\text { Fractal } \\
\text { method }\end{array}$ & $\begin{array}{l}\text { Fractal } \\
\text { dimension }\end{array}$ & $\begin{array}{l}\text { Fracture } \\
\text { toughness } \\
(\mathrm{MPa} \sqrt{\mathrm{m}})\end{array}$ & References \\
\hline IV & Fragmentation & $\begin{array}{l}\text { Basalt, } \\
\text { dunite }\end{array}$ & $\begin{array}{l}\text { Optical } \\
\text { reflection } \\
\text { microscope }\end{array}$ & $40-120 \times$ & $\begin{array}{l}\text { Island- } \\
\text { perimeter }\end{array}$ & $1.13,1.14$ & N/A & $\begin{array}{l}\text { Fujimura } \\
\text { et al. } \\
\text { (1986) }\end{array}$ \\
\hline I & & & & & & $1.12,1.11$ & N/A & \\
\hline I & SR & $\begin{array}{l}\text { Ocala } \\
\text { chert }\end{array}$ & N/A & N/A & $\begin{array}{l}\text { Slit island and } \\
\text { Richardson } \\
\text { plots }\end{array}$ & $1.15-1.32$ & $1.05-1.55$ & $\begin{array}{l}\text { Mecholsky } \\
\text { and } \\
\text { Mackin } \\
(1988)\end{array}$ \\
\hline I & SR & Gabbro & $\begin{array}{l}\text { Cambridge } \\
\text { Quantimet } \\
900\end{array}$ & $100 \times$ & $\begin{array}{l}\text { Vertical } \\
\text { section }\end{array}$ & $\begin{array}{r}1.026- \\
1.030\end{array}$ & $2.69-3.63$ & $\begin{array}{l}\text { Zhang et } \\
\text { al. } \\
\text { (2001) }\end{array}$ \\
\hline III & & & & & & $\begin{array}{r}1.030- \\
1.068\end{array}$ & $\begin{array}{r}6.53- \\
26.98\end{array}$ & \\
\hline I & CB & Sandstone & $\begin{array}{r}\text { 3-D laser } \\
\text { scanner }\end{array}$ & $0.1 \mathrm{~mm}$ & $\begin{array}{l}\text { Roughness } \\
\text { length }\end{array}$ & $2.247 \pm 0.016$ & $1.07-1.26$ & $\begin{array}{l}\text { Backers et } \\
\text { al. } \\
(2003)\end{array}$ \\
\hline I & Ring & Sandstone & N/A & $1 \mu \mathrm{m}$ & $\begin{array}{l}\text { Gaussian } \\
\text { distribution }\end{array}$ & $0.46 \pm 0.05^{b}$ & N/A & $\begin{array}{l}\text { Ponson et } \\
\text { al. } \\
(2007)\end{array}$ \\
\hline II & SENB & Limestone & $\begin{array}{l}\text { Laser } \\
\quad \text { Profilometer }\end{array}$ & N/A & Box covering & $2.0-2.05$ & N/A & $\begin{array}{l}\text { Liu and } \\
\text { Duan } \\
(2009)\end{array}$ \\
\hline I & NSCB & Marble & $\begin{array}{l}\text { 3D laser } \\
\text { profilometry }\end{array}$ & $7 \mu \mathrm{m}$ & $\begin{array}{r}\text { Projective } \\
\text { covering }\end{array}$ & 2.332 & 1.5 & $\begin{array}{l}\text { Zhang and } \\
\text { Zhao } \\
(2013 a)\end{array}$ \\
\hline III & & & & & & 2.156 & $1.65-2.6$ & \\
\hline I & SENB & Coal & $\begin{array}{l}\text { 3D laser } \\
\text { profilometry }\end{array}$ & $7 \mu \mathrm{m}$ & $\begin{array}{r}\text { Projective } \\
\text { covering }\end{array}$ & 2.1594 & 0.0806 & $\begin{array}{c}\text { Zhao et al. } \\
\text { (2013) }\end{array}$ \\
\hline II & & & & & & 2.1424 & 0.793 & \\
\hline
\end{tabular}

a I: Servo-hydraulic machine (e.g., MTS and Instron); II: Drop-weight machine; III: Split Hopkinson pressure bar; IV: Projectile impact technique

${ }^{\mathrm{b}}$ Roughness exponent

loading; Zhang et al. (2001) put forward that the fractal dimension of Fangshan gabbro increased with loading rate; and Backers et al. (2003) argued that surface roughness of sandstone was independent on loading rate. Table 7 summarizes the fractal dimension or the roughness exponent of rock materials under quasistatic and in particular dynamic loading conditions from the literature. The low-resolution of measurement techniques and the complication of microstructures are probably the most significant factors limiting the results. Therefore, qualitative and quantitative micromeasurements on fracture surface are required to interpret failure mechanisms of rocks having different microstructures.

\subsection{Fracture surface morphology}

In a polycrystalline material, mechanically induced microcracks are generally classified as intergranular (IG) microcracks (along the grain boundaries) and transgranular (TG) microcracks (through the grain) (Kranz 1983; Lawn 1993; Thompson and Knott 1993). Cleavage ${ }^{1}$ (along well-developed crystallographic

planes within a single grain) is a subset of TG microcracks but important enough in rocks to be treated

1 In rock mechanics, cleavage is restricted to splitting along specific crystallographic planes. 

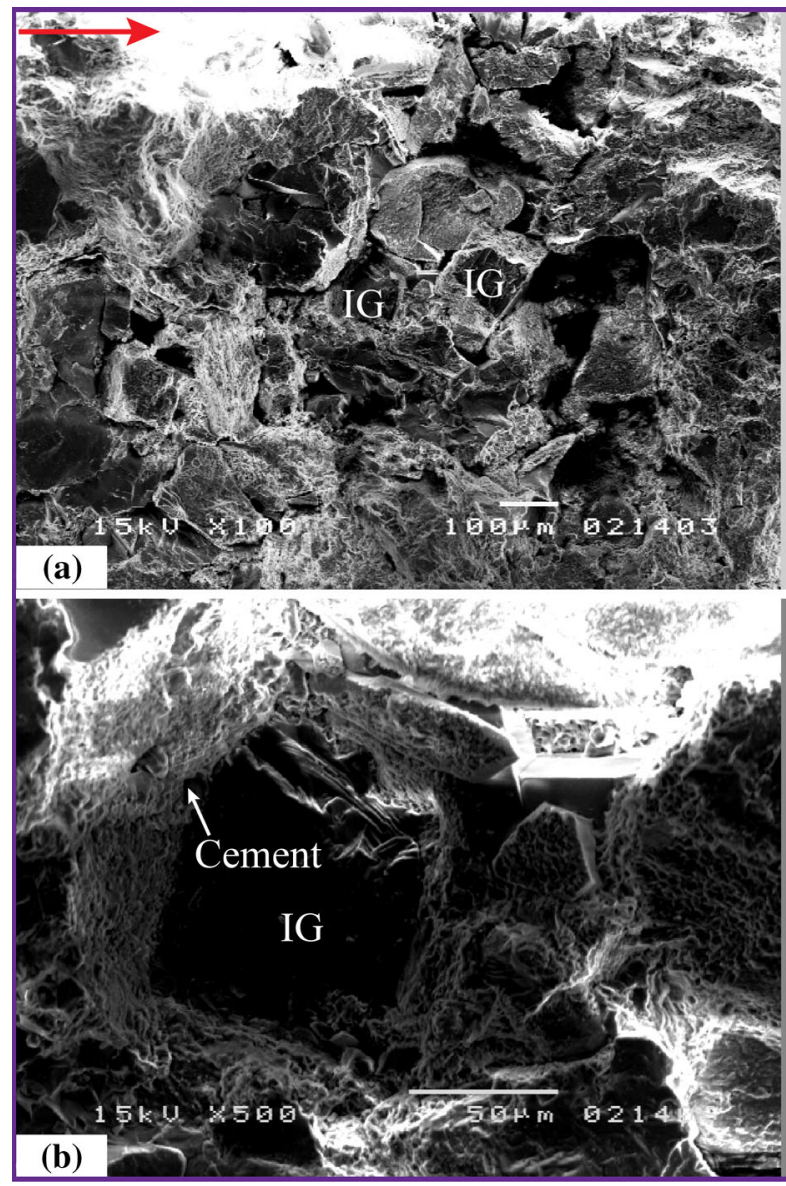

Fig. 8 SEM micrographs of sandstone at increasing magnification of, a, b quasi-static fracture, $\mathbf{c}, \mathbf{d}$ dynamic fracture $(I G$ intergranular microcracks, $T G$ transgranular microcracks, $C F$ con-

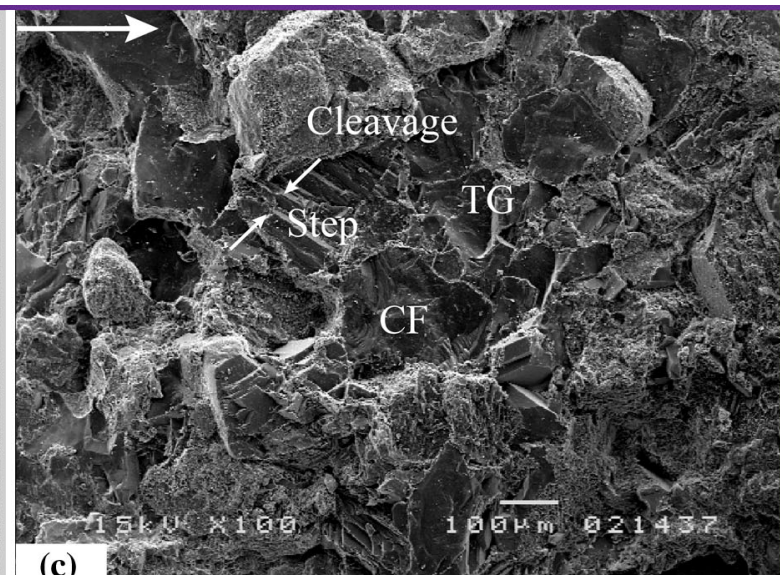

(c)

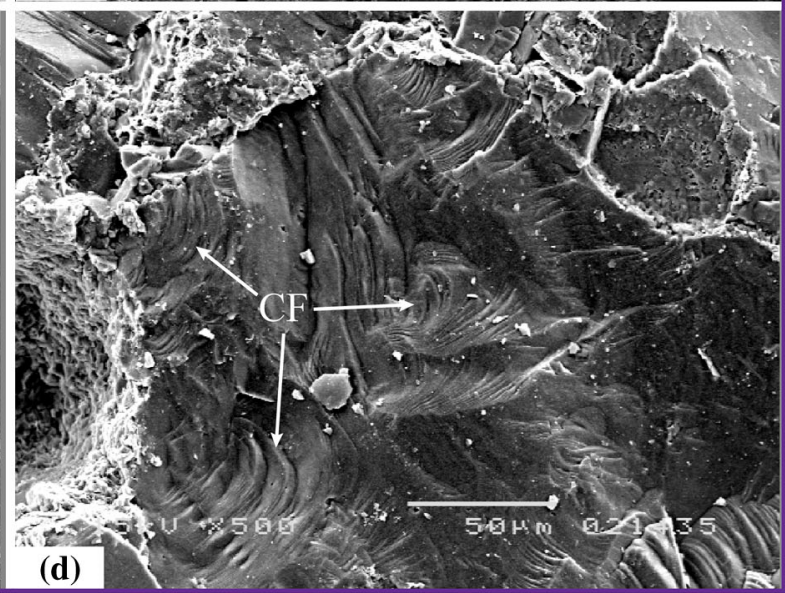

choidal fracture) SEM micrographs in Figs. 8, 9, 10 and 11 were captured at a distance of $\sim 10 \mathrm{~mm}$ from the notch tip. The arrow in each micrograph indicates the direction of crack propagation

ness, as shown in Fig. 8a, b. The induced microcracks propagated primarily along the grain boundaries, though some microcracks propagated across the edge of the grain that could be also regarded as IG microcracks. Several grains pulled out from the cement lead to the surface pits observed at lower magnifications. Under dynamic loads, cleavage steps, multiple micro-conchoidal fracture, and transgranular microcracks associated smooth planar surfaces are frequently observed, as shown in Fig. 8c, d. The smoothly curving conchoidal fracture is a specific feature of quartz (Norton and Atkinson 1981), and multiple microconchoidal fractures are usually dominated by the fast crack propagation.

In igneous rocks, TG microcracks are the major cracking form on both quasi-static and dynamic frac- 

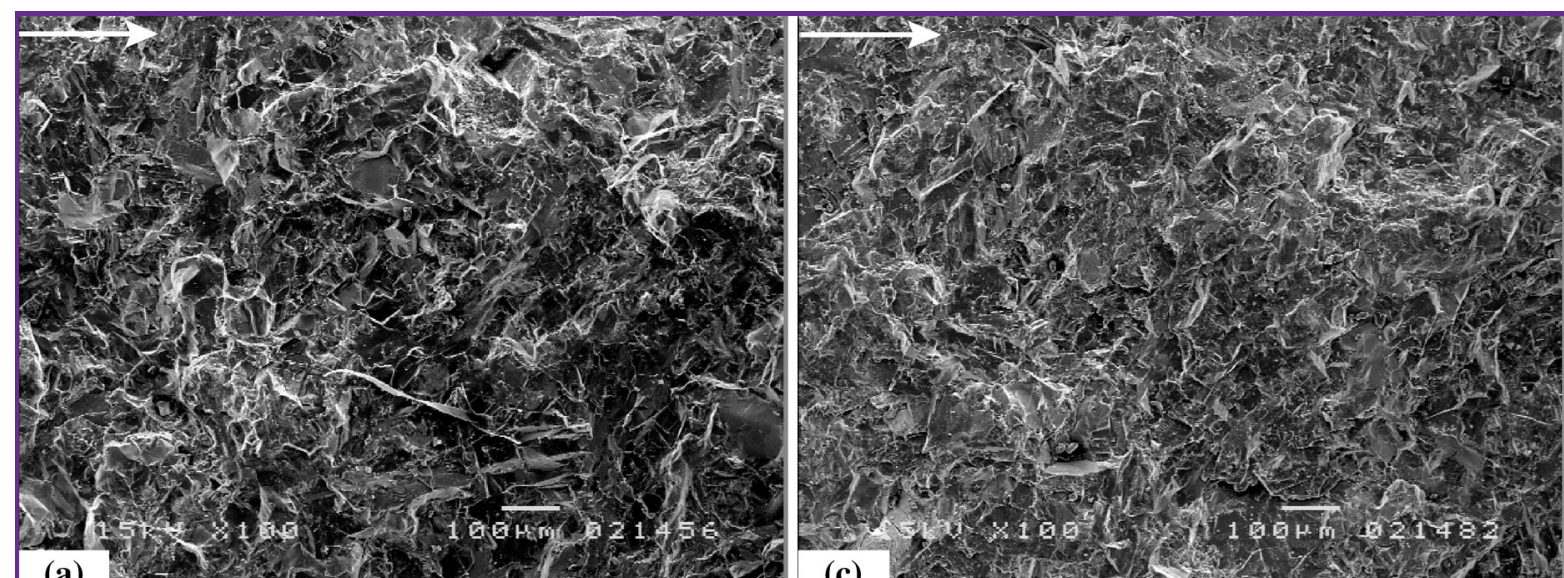

(a)

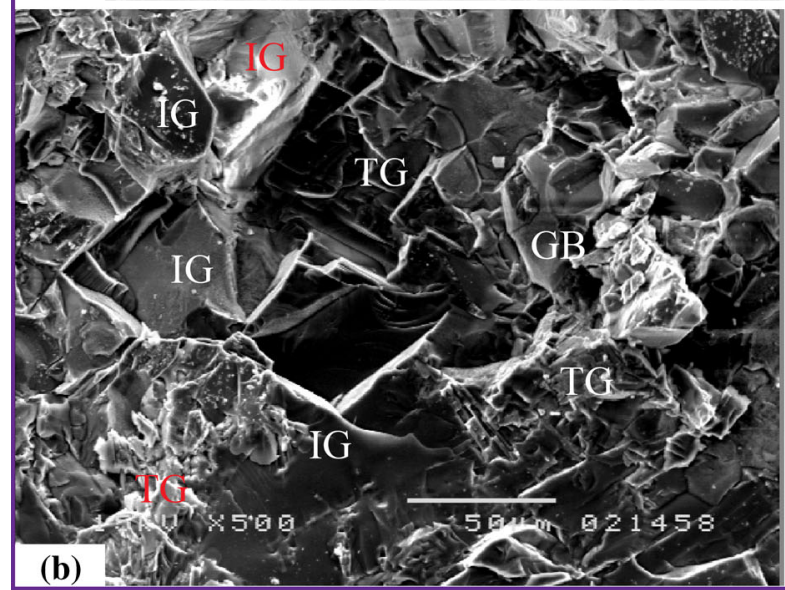

(c)

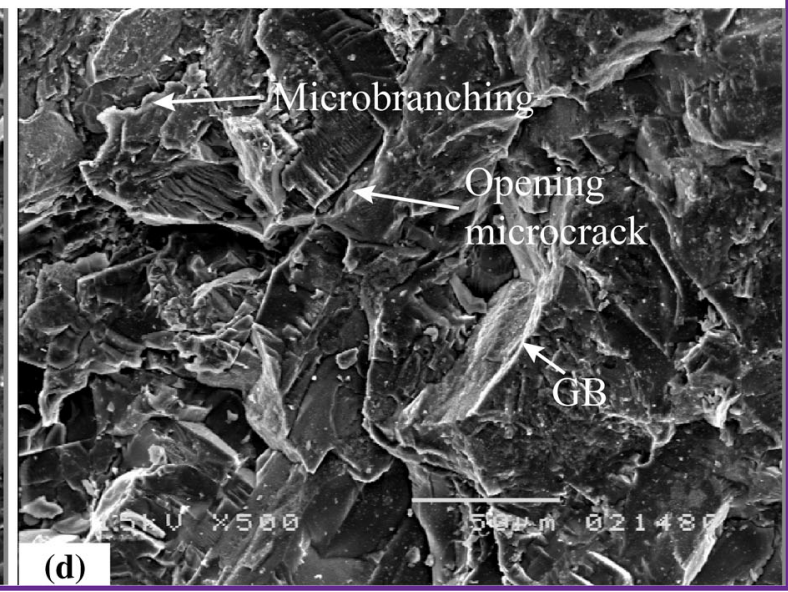

Fig. 9 SEM micrographs of gabbro at increasing magnification of, a, $\mathbf{b}$ quasi-static fracture, $\mathbf{c}, \mathbf{d}$ dynamic fracture ( $G B$ grain boundary)

ture surfaces, as shown in Fig. 9. With the increase of loading rate, TG microcracks become more frequently and there are few or no IG cracks. At the low magnification, the dynamic fracture surface is smooth (see Fig. 9c), while more curved steps are clearly observed in rugged surface at the high magnifications, as shown in Fig. 9d. Moreover, the numbers of opening microcracks and microbranches are increased, as discussed in more details next.

In non-foliated metamorphic rocks, micrographs demonstrated that TG microcracks are influenced by the size of grain and the orientation of the cleavage plane, which occurs more easily in the large grains. The large deflections in CG marble mask the more subtle mist and hackle markings. Usually, this difficulty is compensated for because most large-grained materials fail in a TG microcracks manner and leave classic characteristic markings on the surface, for example, cleav- age marks, river lines, and twist hackle indicators. This river patterns are resulted from the propagating crack deflecting onto parallel planes in local, adjacent regions along the crack front. These regions also result in cleavage steps. The crack frequently propagated through the large grain and induced the catastrophic failure under dynamic loads, as shown in Fig. 10c, d.

In fine-grained marble, there were the predominant IG microcracks with some TG contribution under quasi-static loads (see Fig. 11a, b). At the high loading rate, cleavage and noticeably rugged surfaces with a high degree of TG microcracks occur more easily, as shown in Fig. 11c, d. Figure 12 shows in more detail the change in surface appearance of FG marble as the loading rate increases. The predominant IG microcracks under quasi-static loads indicate clearly that the resistance of grain boundary is weaker than that of the cleavage plane, as shown in Fig. 12a, b. Cleavage steps and 

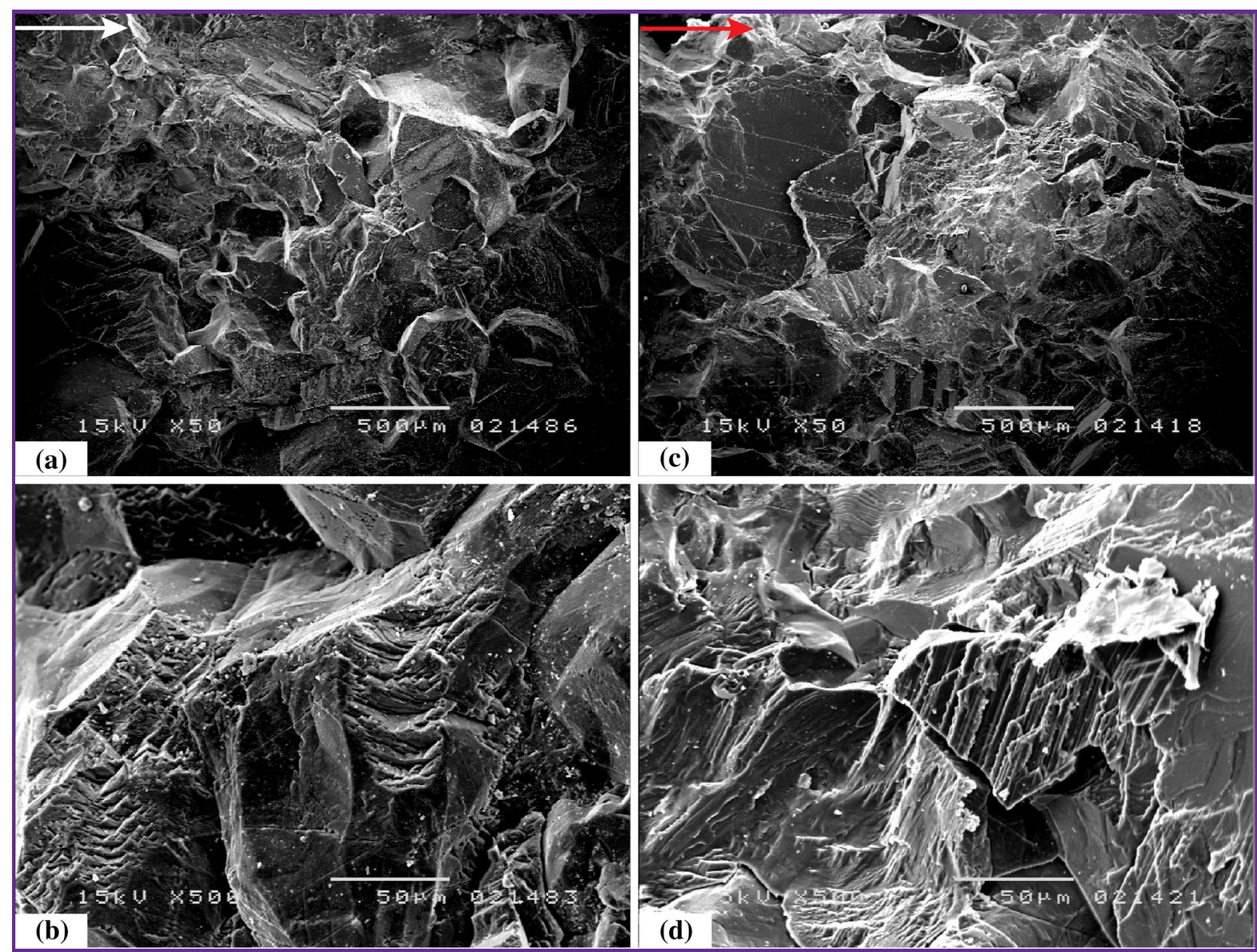

Fig. 10 SEM micrographs of coarse-grained marble at increasing magnification of, a, b quasi-static fracture, $\mathbf{c}, \mathbf{d}$ dynamic fracture

river patterns seldom occur, though a few are observed at high magnifications (see Fig. 12b). Figure 12c, d shows a typical fracture surface at a striking speed $3 \mathrm{~m} / \mathrm{s}$, and TG microcracks are the major cracking form, even though there are some IG microcracks simultaneously. Cleavage occurs on well-developed crystallographic planes and is often observed to take place in parallel sets of various lengths within one grain, as shown in Fig. 12d. The cleavage steps are extremely sharp and virtually parallel except where they gradually merge with uncracked neighbouring grains. The number of planes susceptible to cleavage in a rock is a function of orientation. With the increase of loading rate, the cleavage and opening microcracks become the predominant microcrack types, and there are a few or no IG microcracks, as shown in Fig. 12f. Micrographs also demonstrate that TG microcracks are influenced by the size of grain and the direction of the cleavage plane, which is more common for the large grains than for the small ones.

The cleavage planes perpendicular to the tensile stress have a pure normal stresses across them, and others have a combination of tensile and shear stress acting on the cleavage plane. Cracking parallel to the cleavage plane is accomplished by the lowest energy dissipation, but it requires substantially more energy as the angle increases, as shown in Fig. 13. Thus, there are two modes of energy dissipation during cleavage: (1) the creation of extra stepped surface areas produced by cleavage, and (2) the plastic deformation caused by the shear stress. The shapes of the cleavage steps are heavily controlled by the cleavage plane and loading rate. When the angle of the cleavage planes with the boundary is zero, no steps are formed at the boundary under quasi-static loading. As the angle increases, TG microcracks are not likely to take place and the crack 

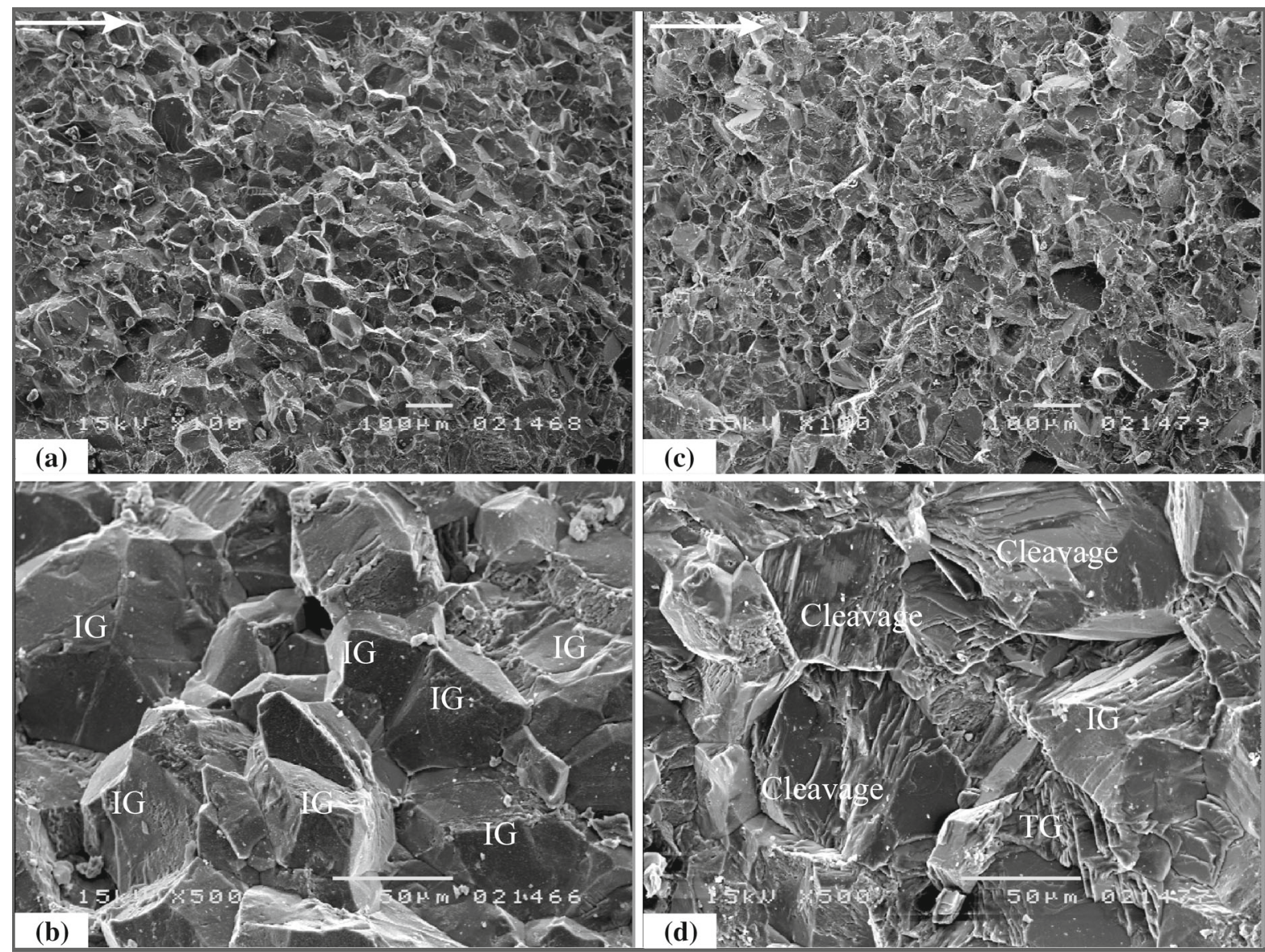

Fig. 11 SEM micrographs of fine-grained marble at increasing magnification of, a-b quasi-static fracture, $\mathbf{c}-\mathbf{d}$ dynamic fracture

propagates normally along the grain boundary instead of crossing it. However, both the steps and TG microcracks often occurred on dynamic fracture surfaces.

Cleavage steps associated with overlapping parallel cracks show the angle of intersection of cleavage planes and obtuse intersection and acute intersection for a crack tilting in direction of crack propagation. Final separation in dolomite has occurred along two sets of cleavage planes $\{010\}$ and $\{100\}$ that meet at an angle of $75^{\circ}$ (acute intersection) and of $105^{\circ}$ (obtuse intersection) on the $\{001\}$ cleavage surface, respectively as shown in Fig. 14a, c. In Fig. 14a, the parallel cleavage steps at an acute angle produce additional resistance to the separation and more extensive overlapping of the cracks, and the step-height is roughly $100 \mu \mathrm{m}$ at this scale. Opening microcracks occur primarily along the direction of crack growth. In contrast with the irregular character of this surface with the relatively flat cleav- age surface, close examination reveals that the fracture surface is covered by river lines and terraces at different scale levels and the step patterns are repeated at even finer scales (Fig. 14b, d).

Figure 15 shows opening microcracks and microbranches nucleated from high-stress concentration regions in different rock types. Surface debris was clearly visible on the fracture surfaces of sandstone and CG marble, as shown in Fig. 15f. Hogan et al. (2012) also observed the phenomenon on the surface of granite after dynamic fragmentation. Highspeed photographs demonstrated that the surface debris is formed on the sandstone and CG marble during fracturing (see Fig. 3a, c) that is caused by TG microcracks.

Figure 16 shows a microcrack nucleated at the quartz boundary and propagated normal to the mode I loading under dynamic loads. The higher stresses and 

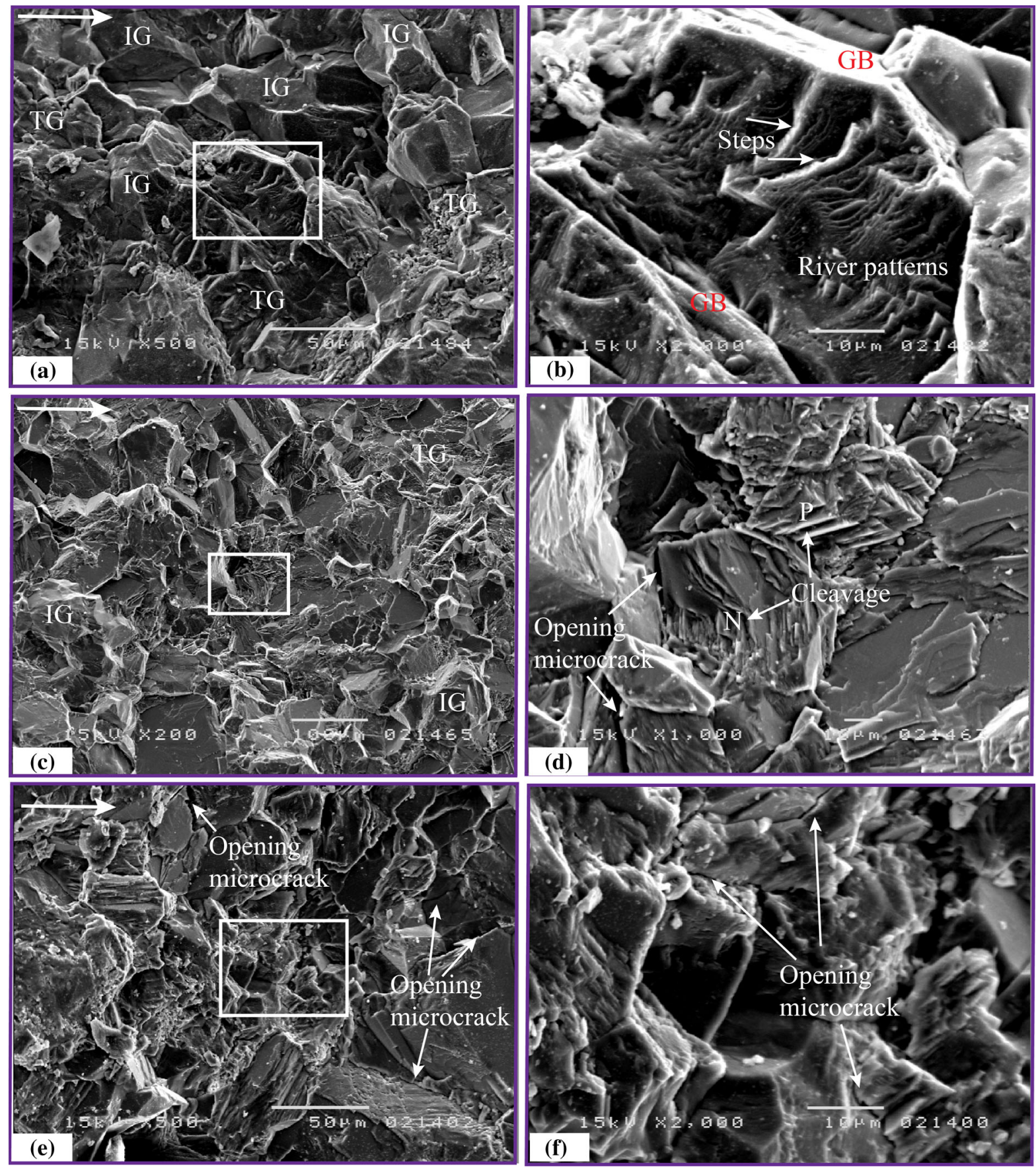

Fig. 12 SEM micrographs of fine-grained marble at increasing magnification of, $\mathbf{a}, \mathbf{b}$ quasi-static fracture, $\mathbf{c}, \mathbf{d}$ dynamic fracture at the striking speed of $3 \mathrm{~m} / \mathrm{s}$ ( $\mathrm{N}$ and $\mathrm{P}$ show cleavage planes that

are normal and parallel to the direction of crack propagation, respectively), e, f dynamic fracture at the striking speed of $5 \mathrm{~m} / \mathrm{s}$

in the roughness of the fracture surface, which lead to the features of mirror, mist and hackle. ical activity at the crack tip and a progressive increase 

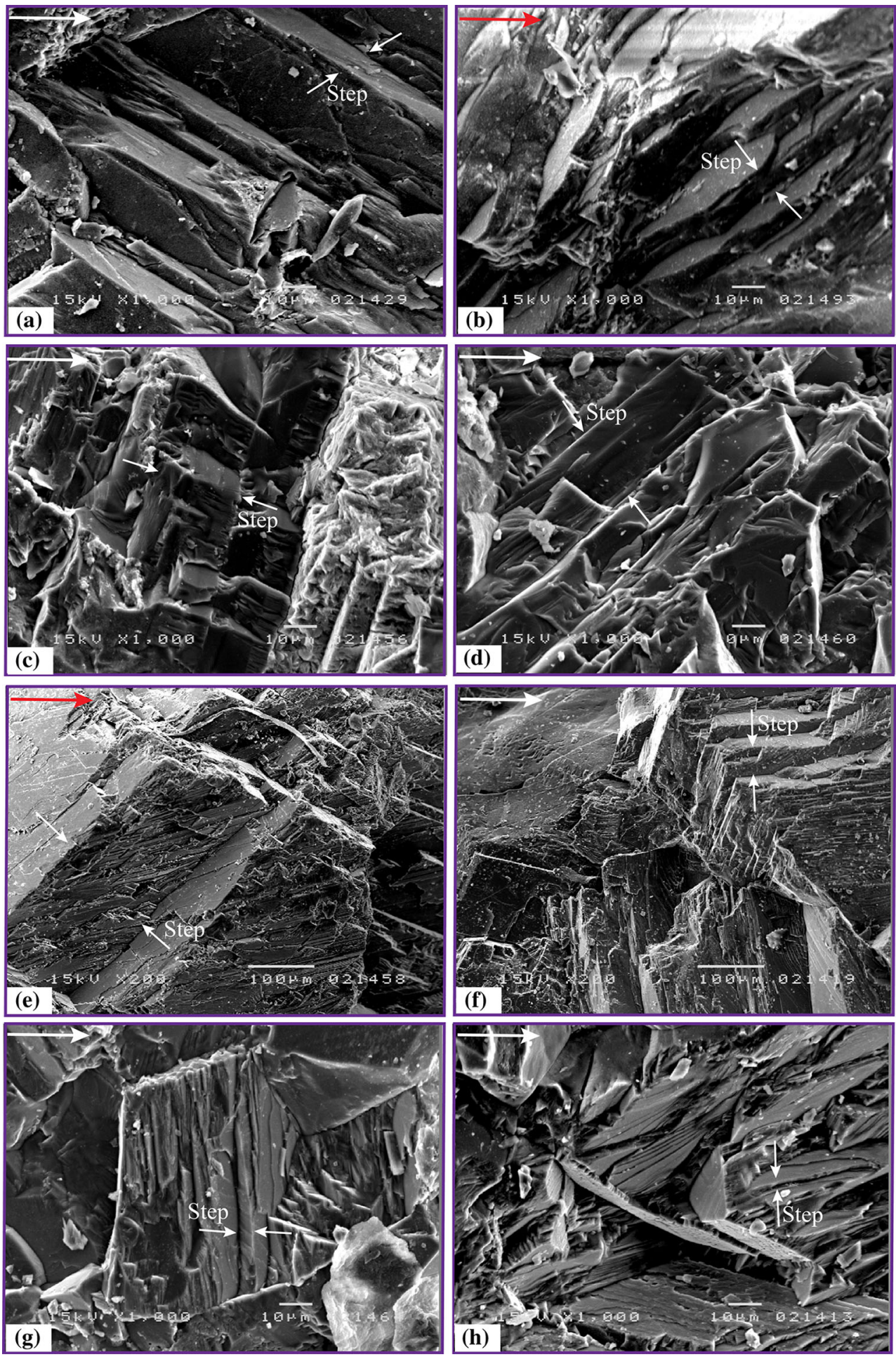

Fig. 13 SEM micrographs of cleavages: parallel to the cleavage plane (left row), $\mathbf{a}$ in sandstone, $\mathbf{c}$ in gabbro, $\mathbf{e}$ in coarse-grained marble, $\mathbf{g}$ in fine-grained marble; and perpendicular to the cleav- age plane (right row), $\mathbf{b}$ in sandstone, $\mathbf{d}$ in gabbro, $\mathbf{f}$ in coarsegrained marble, $\mathbf{h}$ in fine-grained marble, at the striking speed of $3 \mathrm{~m} / \mathrm{s}$ 

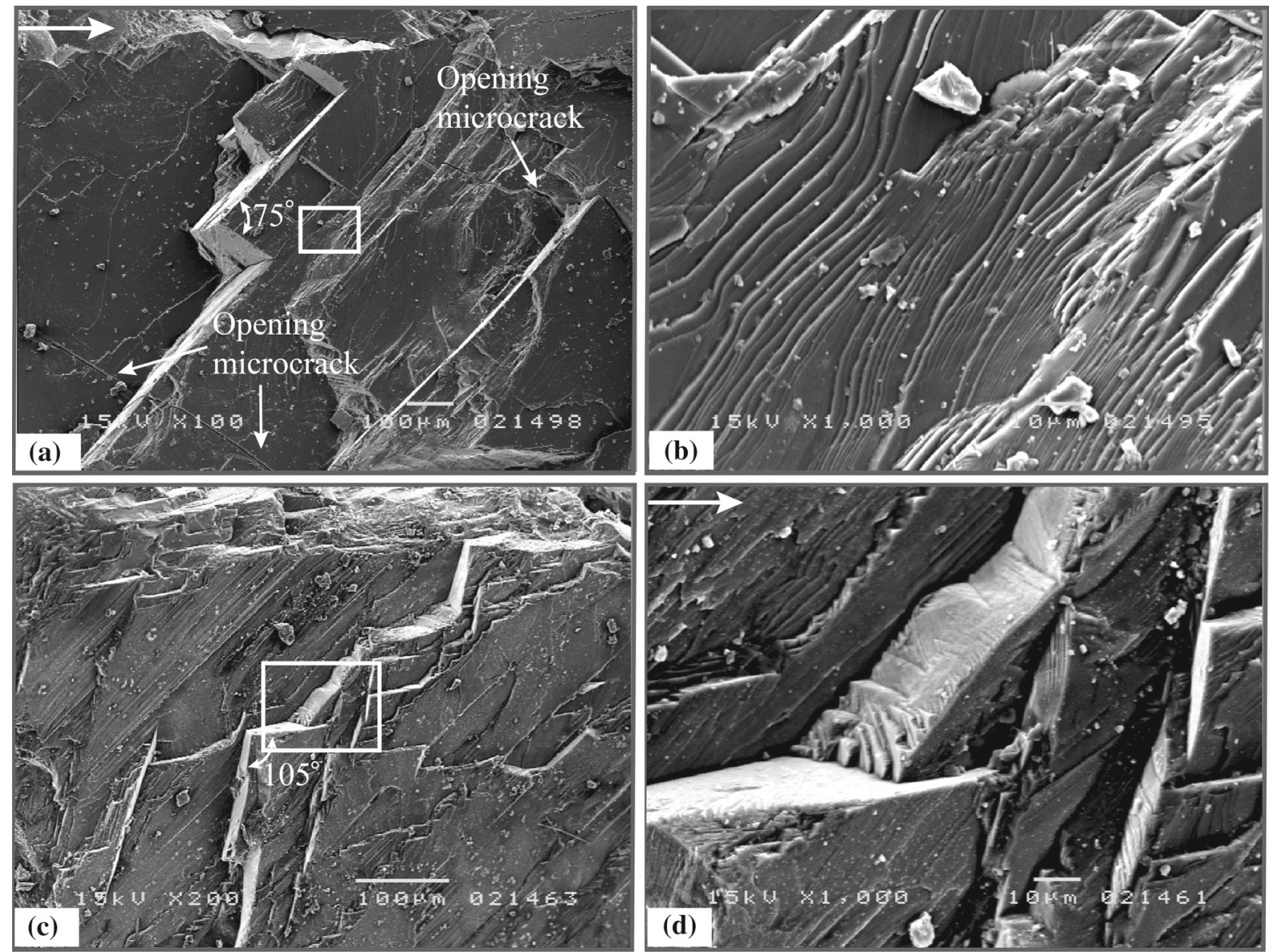

Fig. 14 SEM micrographs of the coarse-grained marble showing, $\mathbf{a}$ an acute intersection for cleavage microcracks on the $\{001\}$ plane of the dolomite, $\mathbf{b}$ river line step pattern on the cleaved

dolomite at a higher magnification,c cleavage dolomite at separation of obtuse overlaps, $\mathbf{d}$ irregular faceted river line steps on cleavage plane of the dolomite, at the striking velocity of $3 \mathrm{~m} / \mathrm{s}$

\subsection{Surface roughness}

The surface roughness is basically associated with failure mechanisms or microcrack modes. In general, the mode of IG microcracks gives rise to a rougher surface, whereas the roughness associated with TG microcracks is flatter but is coupled with more energy dissipation during the crack propagation.

To further study the effect of loading rate on the surface roughness, micromeasurements were conducted using a 3D laser profilometry with a resolution of $7 \mu \mathrm{m}$ (Ju et al. 2007; Zhang and Zhao 2013a). To avoid the influence of some radially angled shear cracks formed at the loading point of the specimen in contact with the end of the incident bar, the length of $2 \mathrm{~mm}$ at this end $(\mathrm{z}=18 \mathrm{~mm})$ was not used for

analysis. Figure 17 illustrates typical 3D surface profiles of fine-grained marble under both quasi-static and dynamic loading conditions, respectively. Fractal dimension $D$ of the fracture surface was calculated to identify the $3 \mathrm{D}$ configuration of fracture surface by applying the projective covering method proposed by Xie and Wang (1999) and Zhou and Xie (2003) in the form:

$N(\xi)=\sum_{i, j=1}^{n-1} N_{i, j}, N(\xi) \sim \xi^{-D}$

where $N(\xi)$ is the total number of covering box, $\xi$ is the covering length, and $D$ is the fractal dimension of the fracture surface. 

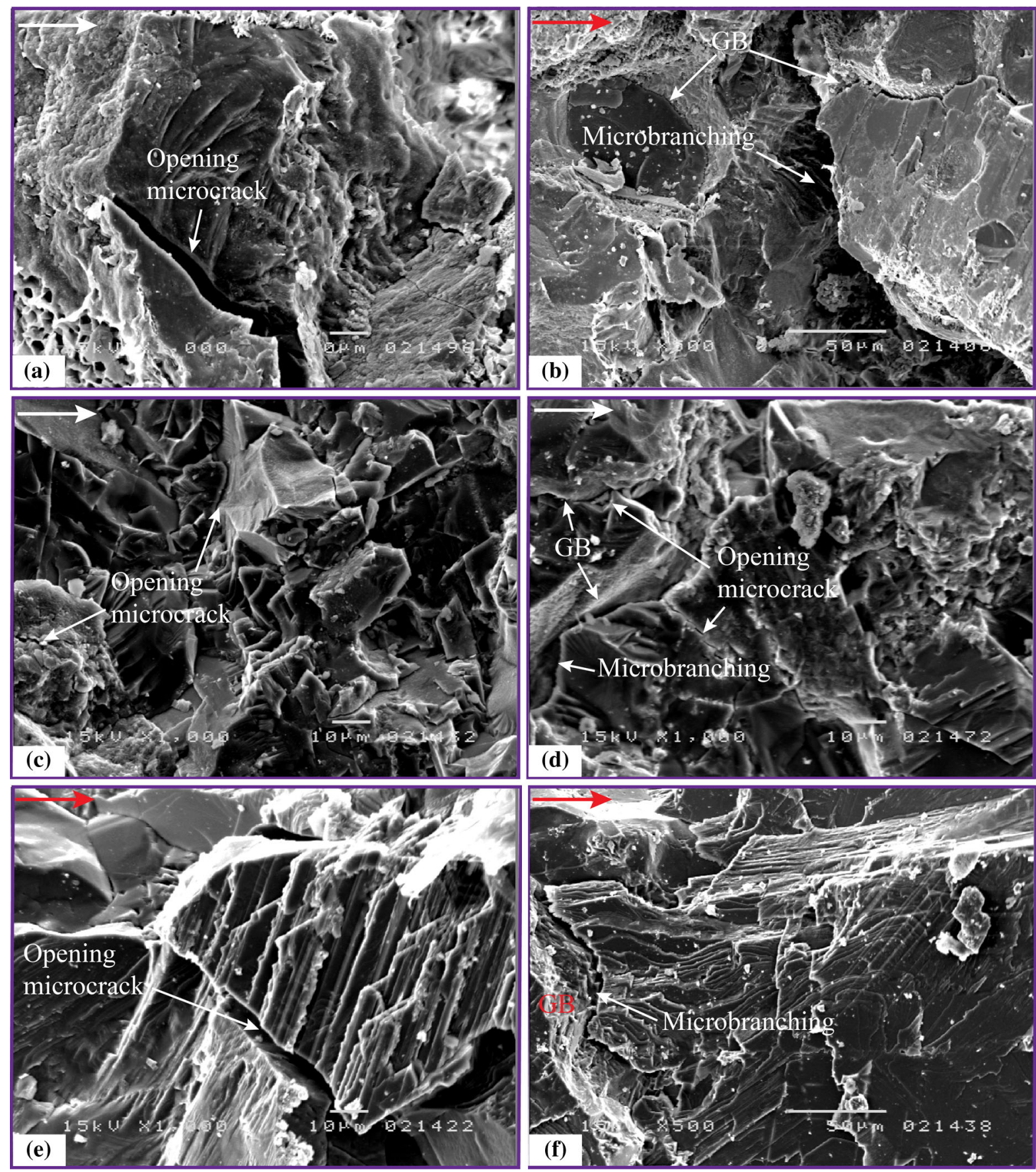

Fig. 15 SEM micrographs showing: opening microcracks nucleated (left row), a from grain boundaries in sandstone, $\mathbf{c}$ on clinopyroxene in gabbro,e on dolomite in coarse-grained marble, and microbranching nucleated (right row): $\mathbf{b}$ at the grain/cement

The covering lengths are chosen in the range from 0.1 to $2 \mathrm{~mm}$, and the relation between the covering length and the number of the covering box is linearly

interface in sandstone, $\mathbf{d}$ grain boundaries in gabbro, $\mathbf{f}$ grain boundaries in coarse-grained marble, at the striking speed of $3 \mathrm{~m} / \mathrm{s}$

fitted in the bi-logarithm coordinate and the slope of the line is value of $D$. Figure 18a shows that the fractal dimension of sandstone is somehow scattered and 


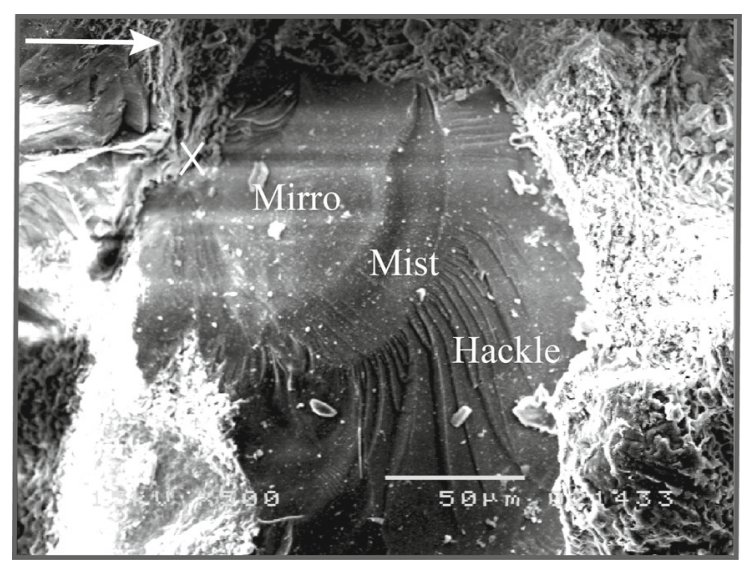

Fig. 16 Fracture surface of dynamically fractured sandstone showing fracture nucleation, mirror, mist and hackle regions on the quartz (The mark $X$ shows where crack reinitiation occurs)
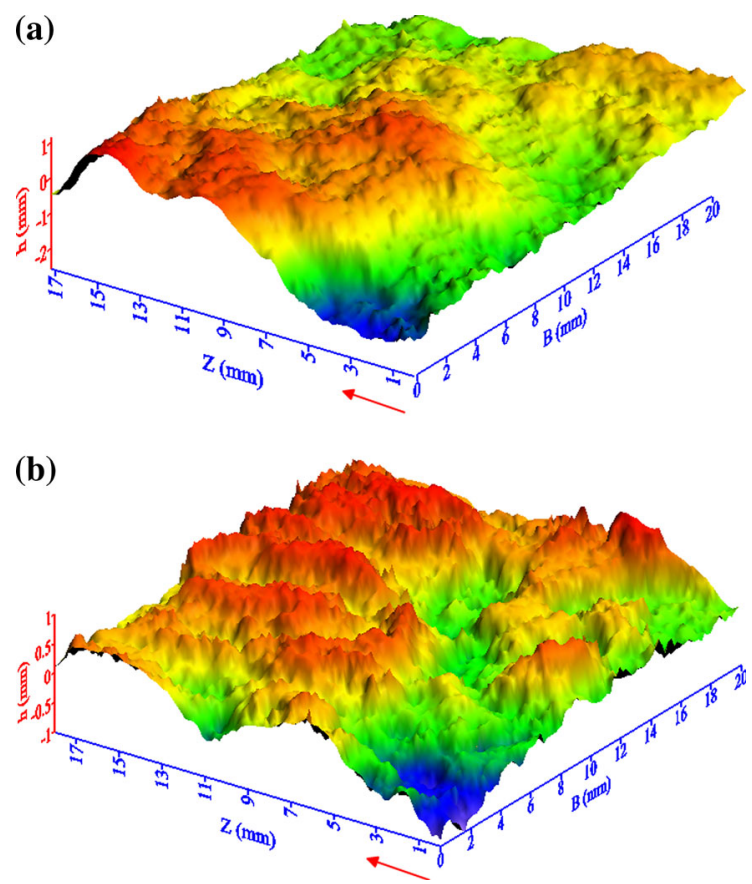

Fig. 17 Fracture surface profiles of fine-grained marble under, a quasi-static loads, b dynamic loads at the striking speed $3 \mathrm{~m} / \mathrm{s}$ (The arrow indicates the direction of crack propagation)

there is no clear trend to indicate the effect of loading rate on the surface roughness. A similar conclusion was reached by Backers et al. (2003) who conducted tests on sandstone under intermediate loadings. This might be caused by the complicated cement fracture and surface pits (see Fig. 8). Figure 18b, d shows a decrease of $D$ with increasing loading rate for gabbro and FG marble. SEM-micrographs in Figs. 8, 11, 13 and 15 also demonstrate that more TG microcracks in particular the cleavage and opening microcracks at higher loading rate leading to a lower value of $D$. Mecholsky and Mackin (1988) reported that the $D$ of IG microcracks in Ocala chert was 0.17 higher than that of TG microcracks. For CG marble, the fractal dimension increases with the increase of loading rate, as shown in Fig. 18d, which is supported by the SEM micrographs in Figs. 10 and 14. TG microcracks, cleavage and opening microcracks are more frequently observed under dynamic loads, and thus the fractal dimension is lower, as reported by (Mecholsky and Mackin 1988). Although the precision of micromeasurement is influenced by the complicated microstructures, the general trend of estimated results somehow exhibits the fracture patterns of rock materials.

Attempts have been made to establish the quantitative relationship between the fractal dimension and the fracture toughness under a wide range of loading rates (Zhang et al. 2001). Surface measurements show that there are extremely hard to identify the opening microcracks, microbranches, plastic deformation, and characteristic markings, while these microcrack modes played an important role in dissipated energies produced by dynamic fracture. The present study indicates that the effects of loading rate on fractal dimension are governed mainly by the microcrack modes and rock microstructures. We attempted to measure fracture surface using an optical interferometer (Wyko NT1100) with a higher resolution. However, due to the large grain size of rocks, the fringes produced by the optical interferometer could not be fully reflected from the lower parts. Although it was not able to get any reliable results, it was worth being reported here.

\section{Conclusions}

Notched semi-circular bending tests were performed to study quasi-static and dynamic fracture behaviour of four well-studied rock types. On-specimen strain gauges and high-speed photography were used to determine dynamic fracture parameters at the macroscopic scale. The fracture surfaces were qualitatively and quantitatively investigated by conducting fractographic examination and roughness measurements. The main conclusions of this study are as follows: 

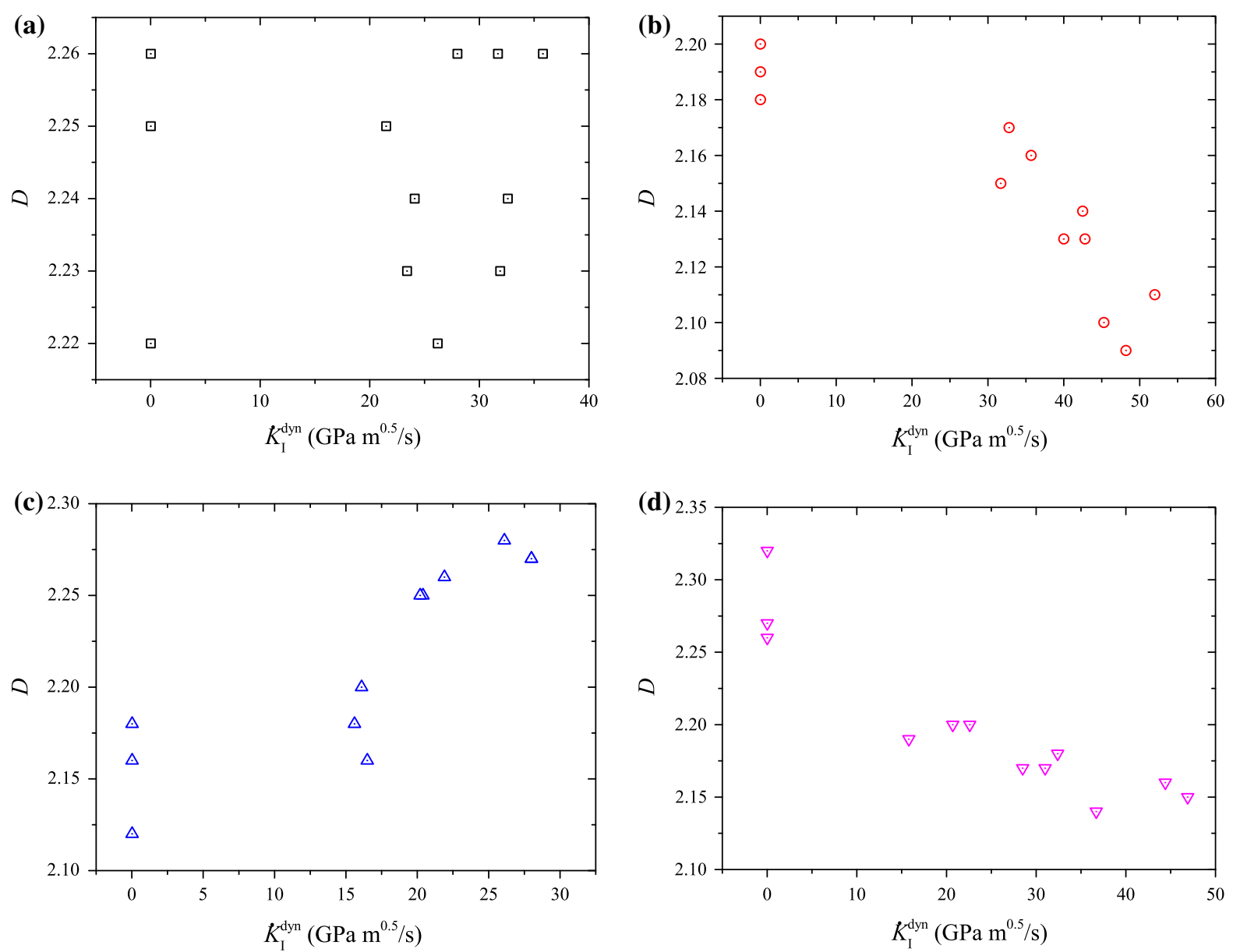

Fig. 18 The fractal dimension as a function of loading rate for: a sandstone, $\mathbf{b}$ gabbro, $\mathbf{c}$ coarse-grained marble, $\mathbf{d}$ fine-grained marble

(1) The dynamic crack initiation toughness was obtained from the quasi-static analysis that was evidenced by the force equilibrium until the time to fracture. The crack speed and velocity of flying fragments were quantitatively determined from high-speed photographs. The dynamic fracture energy was estimated from the velocity of flying fragments, the absorbed energy and fracture surface area of the specimen, which increased rapidly with the increase of crack speed. The dynamic crack growth toughness was then derived from well-known Irwin's correlation at a specific crack speed.

(2) The dynamic crack initiation and growth toughness of four rock types were dependent on the loading rate, and the rate-sensitivity of growth toughness was more evident than that of the former. The degrees of normalized crack initiation toughness in gabbro and fine-grained marble were apparently higher than those in sandstone and coarse-grained marble, which were mainly governed by the time of stress wave required to travel through the specimen. The higher growth toughness was associated with a greater degree of transgranular microcracks.

(3) The SEM fractographic studies revealed that the operating failure mechanisms under dynamic loads were mostly of transgranular microcracks. With the increase of loading rate, the number of typical microcrack modes, such as multiple cleavage steps, opening microcracks and microbranches, was increased. The increase in surface area generated by these typical modes were responsible for large energy dissipation (through the formation of extra surface areas), while it could not be identified well by the surface roughness measurements. 
(4) The fractal dimension was dependent primarily on microcrack modes and rock microstructure. Due to the complicated cement fracture and surface pits in sandstone, the fractal dimension does not depend on the loading rate. In coarse-grained marble, the mode of transgranular microcracks gave rise to a rougher surface, whereas the roughness with more intergranular microcracks was much flatter. The conclusion was opposite to fine-grained gabbro and marble, in which the transgranular microcracks were coupled with more energy dissipation during crack propagation.

Acknowledgments This work was supported by the Swiss National Science Foundation (No. 200020_129757). The authors thank Prof. Xiao Li and Dr. Changyu Liang of Chinese Academy of Sciences for their help in specimen preparation, Prof. Xibing $\mathrm{Li}$ and Dr. Zhiqiang Yin of Central South University for helping us perform experiments with the split Hopkinson pressure bar, Prof. Yang Ju and Dr. Ruidong Peng of China University of
Mining and Technology (Beijing) for their help on experiments using the optical profilometry and SEM, and Drs. Daniel Bonamy and Laurent Ponson of the Group Complex Systems and Fracture, CEA-SACLAY, France, for their fruitful discussions on the analysis of fracture surface. The authors would like to thank two anonymous reviewers for their comments that help improve the manuscript.

\section{Appendix}

Experimental data under dynamic loading conditions are tabulated in Table 8, including the loading rate $\dot{K}_{\mathrm{I}}^{\text {dyn }}$, the time to fracture $t_{\mathrm{f}}$, the dynamic crack initiation toughness $K_{\text {Id }}$, the crack speed $v$, the dissipated energy $\Omega$, the dynamic fracture energy $G_{\mathrm{dC}}$, the calculated dynamic crack propagation toughness $K_{\mathrm{ID}}$, and the fractal dimension $D$.

Table 9 lists the optical and physical properties of the primary minerals in selected four rock types.

Table 8 Experimental results of rock materials under dynamic loading conditions

\begin{tabular}{|c|c|c|c|c|c|c|c|c|}
\hline Specimen no. ${ }^{\mathrm{a}}$ & $\dot{K}_{\mathrm{I}}^{\mathrm{dyn}}(\mathrm{GPa} \sqrt{\mathrm{m}} / \mathrm{s})$ & $t_{\mathrm{f}}(\mu \mathrm{s})$ & $K_{\mathrm{Id}}(\mathrm{MPa} \sqrt{\mathrm{m}})$ & $v(\mathrm{~m} / \mathrm{s})$ & $\Omega(\mathrm{J})$ & $G_{\mathrm{dC}}\left(\mathrm{J} / \mathrm{m}^{2}\right)$ & $K_{\mathrm{ID}}(\mathrm{MPa} \sqrt{\mathrm{m}})$ & $D$ \\
\hline S1-SG2 & 23.4 & 50 & 1.11 & 297 & 0.04 & 50.8 & 1.16 & 2.23 \\
\hline S2-SG4 & 21.5 & 52 & 1.06 & 311 & 0.06 & 73.1 & 1.39 & 2.25 \\
\hline S3-CPG & 24.1 & 49 & 1.12 & 329 & 0.04 & 51.0 & 1.16 & 2.24 \\
\hline S4-SG2 & 28.0 & 46 & 1.23 & 378 & 0.10 & 121.0 & 1.78 & 2.26 \\
\hline S5-SG4 & 26.2 & 47 & 1.17 & 432 & 0.14 & 176.5 & 2.14 & 2.22 \\
\hline S6-CPG & 31.9 & 48 & 1.27 & 459 & 0.21 & 265.9 & 2.62 & 2.23 \\
\hline S7-SG2 & 35.8 & 42 & 1.36 & 522 & 0.32 & 397.0 & 3.18 & 2.26 \\
\hline S8-SG4 & 32.6 & 40 & 1.30 & 567 & 0.44 & 546.1 & 3.71 & 2.24 \\
\hline S9-CPG & 31.7 & 42 & 1.44 & 648 & 0.81 & 1001.9 & 4.97 & 2.26 \\
\hline G1-SG2 & 31.7 & 48 & 2.56 & 480 & 0.02 & 29.0 & 1.74 & 2.15 \\
\hline G2-SG4 & 32.8 & 47 & 2.56 & 582 & 0.04 & 54.1 & 2.37 & 2.17 \\
\hline G3-CPG & 35.7 & 46 & 2.72 & 432 & 0.03 & 33.3 & 1.86 & 2.16 \\
\hline G4-SG2 & 42.5 & 40 & 2.82 & 752 & 0.09 & 116.3 & 3.45 & 2.14 \\
\hline G5-SG4 & 40.0 & 42 & 2.79 & 816 & 0.12 & 155.0 & 3.97 & 2.13 \\
\hline G6-CPG & 42.8 & 40 & 2.84 & 864 & 0.21 & 258.2 & 5.11 & 2.13 \\
\hline G7-SG2 & 45.3 & 38 & 2.86 & 928 & 0.27 & 336.3 & 5.81 & 2.10 \\
\hline G8-SG4 & 48.2 & 36 & 2.88 & 1,005 & 0.38 & 468.1 & 6.82 & 2.09 \\
\hline G9-CPG & 52.0 & 35 & 3.02 & 1,120 & 0.72 & 885.2 & 9.30 & 2.11 \\
\hline CM1-SG2 & 15.6 & 68 & 0.89 & 187 & 0.04 & 52.2 & 0.94 & 2.18 \\
\hline CM2-SG4 & 16.5 & 62 & 0.86 & 218 & 0.05 & 65.4 & 1.05 & 2.16 \\
\hline CM3-CPG & 16.1 & 66 & 0.89 & 247 & 0.06 & 76.1 & 1.13 & 2.2 \\
\hline CM4-SG2 & 20.4 & 55 & 0.94 & 319 & 0.08 & 92.8 & 1.24 & 2.25 \\
\hline CM5-SG4 & 21.9 & 52 & 0.96 & 377 & 0.10 & 118.2 & 1.39 & 2.26 \\
\hline CM6-CPG & 20.2 & 56 & 0.95 & 348 & 0.08 & 99.5 & 1.28 & 2.25 \\
\hline
\end{tabular}


Table 8 continued

\begin{tabular}{|c|c|c|c|c|c|c|c|c|}
\hline Specimen no. ${ }^{\mathrm{a}}$ & $\dot{K}_{\mathrm{I}}^{\mathrm{dyn}}(\mathrm{GPa} \sqrt{\mathrm{m}} / \mathrm{s})$ & $t_{\mathrm{f}}(\mu \mathrm{s})$ & $K_{\mathrm{Id}}(\mathrm{MPa} \sqrt{\mathrm{m}})$ & $v(\mathrm{~m} / \mathrm{s})$ & $\Omega(\mathrm{J})$ & $G_{\mathrm{dC}}\left(\mathrm{J} / \mathrm{m}^{2}\right)$ & $K_{\mathrm{ID}}(\mathrm{MPa} \sqrt{\mathrm{m}})$ & $D$ \\
\hline CM7-SG2 & 28.0 & 48 & 0.98 & 406 & 0.12 & 150.0 & 1.56 & 2.27 \\
\hline CM8-SG4 & 26.1 & 46 & 1.01 & 435 & 0.15 & 179.5 & 1.70 & 2.28 \\
\hline CM9-CPG & 28.0 & 44 & 1.03 & 479 & 0.18 & 217.9 & 1.86 & 2.27 \\
\hline FM1-SG2 & 20.7 & 55 & 1.14 & 433 & 0.04 & 52.4 & 2.295 & 2.20 \\
\hline FM2-SG4 & 15.8 & 67 & 1.06 & 325 & 0.08 & 102.7 & 3.225 & 2.19 \\
\hline FM3-CPG & 22.6 & 52 & 1.17 & 483 & 0.10 & 122.1 & 3.495 & 2.20 \\
\hline FM4-SG2 & 28.5 & 47 & 1.34 & 673 & 0.34 & 422.8 & 6.435 & 2.17 \\
\hline FM5-SG4 & 31.0 & 46 & 1.43 & 660 & 0.37 & 456.2 & 6.69 & 2.17 \\
\hline FM6-CPG & 32.4 & 44 & 1.43 & 693 & 0.37 & 459.9 & 6.702 & 2.18 \\
\hline FM7-SG2 & 44.4 & 39 & 1.73 & 871 & 0.76 & 940.9 & 9.45 & 2.16 \\
\hline FM8-SG4 & 36.7 & 42 & 1.54 & 829 & 0.92 & 1149.7 & 10.485 & 2.14 \\
\hline FM9-CPG & 46.9 & 37 & 1.74 & 924 & 1.11 & 1375.9 & 11.37 & 2.15 \\
\hline
\end{tabular}

${ }^{\text {a }} S G 2$ two strain gauges, $S G 4$ four strain gauges, $C P G$ Crack propagation gauge

Table 9 Summary of the optical and physical properties of primary minerals in selected rock materials

\begin{tabular}{|c|c|c|c|}
\hline Mineral type & $\begin{array}{l}\text { Crystal } \\
\text { system }\end{array}$ & Cleavage plane & Twinning \\
\hline Quartz & Hexagonal & $\begin{array}{l}\text { Poor/Indistinct } \\
\quad\{10 \overline{1} 1\}\end{array}$ & Not observed \\
\hline Plagioclase & Triclinic & $\begin{array}{l}\{001\} \text { perfect } \\
\{010\} \text { distinct } \\
\text { The cleavages } \\
\text { intersect at } 93^{\circ} \\
\text { to } 94^{\circ}\end{array}$ & $\begin{array}{l}\text { Albite }(010) \\
\text { composition } \\
\text { plane, } \\
\text { polysynthetic } \\
\text { twinning }\end{array}$ \\
\hline Clinopyroxen & Monoclinic & $\begin{array}{l}\{110\} \text { The } \\
\text { cleavages } \\
\text { intersect at } \\
\text { about } 90^{\circ}\end{array}$ & $\begin{array}{l}\text { Simple and } \\
\text { lamellar twins } \\
\text { and } \\
\text { composition } \\
\text { planes }\end{array}$ \\
\hline Dolomite & Hexagonal & $\begin{array}{l}\{10 \overline{1} 1\} \text { Angle } \\
\text { between } \\
\text { cleavages is } \\
74^{\circ} 57^{\prime}\end{array}$ & $\begin{array}{l}\text { Lamellar twins } \\
\text { parallel to one } \\
\text { edge of the } \\
\text { cleavage rhomb } \\
\text { or along its } \\
\text { long diagonal }\end{array}$ \\
\hline
\end{tabular}

\section{References}

ASTM (2011) E1820-11 Standard test method for measurement of fracture toughness. Annual Book of ASTM Standards. ASTM International, West Conshohocken

Atkinson BK (ed) (1987) Fracture mechanics of rock. Academic Press, London

Atkinson C, Smelser RE, Sanchez J (1982) Combined mode fracture via the cracked Brazilian disk test. Int J Fract 18(4):279291. doi:10.1007/bf00015688

Backers T, Fardin N, Dresen G, Stephansson O (2003) Effect of loading rate on mode I fracture toughness, roughness and micromechanics of sandstone. Int J Rock Mech Min 40(3):425-433. doi:10.1016/s1365-1609(03)00015-7

Bazant ZP, Bai SP, Gettu R (1993) Fracture of rock: effect of loading rate. Eng Fract Mech 45(3):393-398. doi:10.1016/ 0013-7944(93)90024-m

Bertram A, Kalthoff JF (2003) Crack propagation toughness of rock for the range of low to very high crack speeds. Key Eng Mater 251-252:423-430. doi:10.4028/www.scientific. net/KEM.251-252.423

Bieniawski ZT (1968) Fracture dynamics of rock. Int J Fract Mech 4(4):415-430. doi:10.1007/bf00186807

Bonamy D, Bouchaud E (2011) Failure of heterogeneous materials: a dynamic phase transition? Phys Rep 498(1):1-44. doi:10.1016/j.physrep.2010.07.006

Cadoni E (2010) Dynamic characterization of orthogneiss rock subjected to intermediate and high strain rates in tension. Rock Mech Rock Eng 43(6):667-676. doi:10.1007/ s00603-010-0101-x

Chen R, Xia K, Dai F, Lu F, Luo SN (2009) Determination of dynamic fracture parameters using a semi-circular bend technique in split Hopkinson pressure bar testing. Eng Fract Mech 76(9):1268-1276. doi:10.1016/j.engfracmech.2009. 02.001

Clarke KC (1986) Computation of the fractal dimension of topographic surfaces using the triangular prism surface area method. Comput Geosci 12(5):713-722. doi:10.1016/ 0098-3004(86)90047-6

Clayton J (2010) Deformation, fracture, and fragmentation in brittle geologic solids. Int J Fract 163(1):151-172. doi:10. 1007/s10704-009-9409-5

Costin LS (1981) Static and dynamic fracture behaviour of oil shale. In: Freiman SW, Fuller ER (eds) Fracture mechanics for ceramics, rock and concrete, ASTM STP 745, vol 745. American Society for Testing and Materials, Philadelphia, pp 169-184

Curbach M, Eibl J (1990) Crack velocity in concrete. Eng Fract Mech 35(1-3):321-326. doi:10.1016/ 0013-7944(90)90210-8 
Dai F, Chen R, Iqbal MJ, Xia K (2010) Dynamic cracked chevron notched Brazilian disc method for measuring rock fracture parameters. Int J Rock Mech Min 47(4):606-613. doi:10. 1016/j.ijrmms.2010.04.002

Dai F, Chen R, Xia K (2010b) A semi-circular bend technique for determining dynamic fracture toughness. Exp Mech 50(6):783-791. doi:10.1007/s11340-009-9273-2

Dai F, Xia K, Zheng H, Wang YX (2011) Determination of dynamic rock mode-I fracture parameters using cracked chevron notched semi-circular bend specimen. Eng Fract Mech 78(15):2633-2644. doi:10.1016/j.engfracmech.2011. 06.022

Dally JW, Fourney WL, Irwin GR (1985) On the uniqueness of the stress intensity factor-crack velocity relationship. Int J Fract 27(3):159-168. doi:10.1007/bf00017965

Du J, Yon JH, Hawkins NM, Arakawa K, Kobayashi AS (1992) Fracture process zone for concrete for dynamic loading. ACI Matert J 89(3):252-258

Eremenko A, Novikov S, Sinitsyn V, Pushkov V, Yakupov M (1996) Determination of fracture toughness and fracture energy of brittle materials under impact wedging. J Appl Mech Tech Phys 37(4):586-594. doi:10.1007/bf02369738

Field J (1971) Brittle fracture: its study and application. Contemp Phys 12(1):1-31. doi:10.1080/00107517108205103

Fischer MP, Elsworth D, Alleyamp RB, Engelder T (1996) Finite element analysis of the modified ring test for determining mode I fracture toughness. Int J Rock Mech Min 33(5):1-15. doi:10.1016/0148-9062(96)89926-8

Forquin P (2012) An optical correlation technique for characterizing the crack velocity in concrete. Eur Phys J Spec Top 206:89-95. doi:10.1140/epjst/e2012-01590-6

Foster JT, Chen W, Luk VK (2011) Dynamic crack initiation toughness of 4340 steel at constant loading rates. Eng Fract Mech 78(6):1264-1276. doi:10.1016/j.engfracmech. 2011.02.019

Fowell RJ (1995) Suggested method for determining mode I fracture toughness using cracked chevron notched Brazilian disc (CCNBD) specimens. Int J Rock Mech Min 32(1):57-64. doi:10.1016/0148-9062(94)00015-u

Fujimura A, Takagi Y, Furumoto M, Mizutani H (1986) Fractal dimensions of fracture surfaces of rock fragments. Mem Natl Inst Polar Res Spec Publ 41:348-357

Gong FQ, Zhao GF (2014) Dynamic indirect tensile strength of sandstone under different loading rates. Rock Mech Rock Eng 1-8. doi:10.1007/s00603-013-0503-7

Hoek E, Bieniawski ZT (1965) Brittle fracture propagation in rock under compression. Int J Fract Mech 1(3):137-155. doi:10.1007/bf00186851

Hogan JD, Rogers RJ, Spray JG, Boonsue S (2012) Dynamic fragmentation of granite for impact energies of 6-28. J Eng Fract Mech 79:103-125. doi:10.1016/j.engfracmech.2011. 10.006

Hu G, Ramesh KT, Cao B, McCauley JW (2011) The compressive failure of aluminum nitride considered as a model advanced ceramic. J Mech Phys Solids 59(5):1076-1093. doi:10.1016/j.jmps.2011.02.003

Jiang F, Vecchio KS (2009) Hopkinson bar loaded fracture experimental technique: a critical review of dynamic fracture toughness tests. Appl Mech Rev 62(6):060802-060839. doi:10. $1115 / 1.3124647$
Ju Y, Sudak L, Xie H (2007) Study on stress wave propagation in fractured rocks with fractal joint surfaces. Int J Sol Struct 44(13):4256-4271. doi:10.1016/j.ijsolstr.2006.11.015

Kalthoff JF (1986) Fracture behavior under high rates of loading. Eng Fract Mech 23(1):289-298. doi:10.1016/ 0013-7944(86)90193-1

Kim Y, Chao Y (2007) Effect of loading rate on dynamic fracture initiation toughness of brittle materials. Int J Fract 145(3):195-204. doi:10.1007/s10704-007-9114-1

Kipp ME, Grady DE, Chen EP (1980) Strain-rate dependent fracture initiation. Int J Fract 16(5):471-478. doi:10.1007/ bf00016585

Klepaczko JR, Bassim MN, Hsu TR (1984) Fracture toughness of coal under quasi-static and impact loading. Eng Fract Mech 19(2):305-316. doi:10.1016/0013-7944(84)90025-0

Kranz RL (1983) Microcracks in rocks: a review. Tectonophysics 100(1-3):449-480. doi:10.1016/0040-1951(83)90198-1

Kuruppu MD (1997) Fracture toughness measurement using chevron notched semi-circular bend specimen. Int J Fract 86(4):L33-L38

Kuruppu MD, Obara Y, Ayatollahi MR, Chong KP, Funatsu T (2014) ISRM-Suggested method for determining the mode I static fracture toughness using semi-circular bend specimen. Rock Mech Rock Eng 47(1):267-274. doi:10.1007/ s00603-013-0422-7

Lagunov VA, Mambetov SA (1965) The rate of growth of cracks in rock specimens. J Appl Mech Tech Phys 6(6):64-66. doi:10.1007/bf00919315

Lambert DE, Ross AC (2000) Strain rate effects on dynamic fracture and strength. Int J Impact Eng 24(10):985-998. doi:10. 1016/s0734-743x(00)00027-0

Lawn B (1993) Fracture of brittle solids. Cambridge University Press, London

Li X, Zou Y, Zhou Z (2014) Numerical simulation of the rock SHPB test with a special shape striker based on the discrete element method. Rock Mech Rock Eng 1-17. doi:10.1007/ s00603-013-0484-6

Li XB, Lok TS, Zhao J (2005) Dynamic characteristics of granite subjected to intermediate loading rate. Rock Mech Rock Eng 38(1):21-39. doi:10.1007/s00603-004-0030-7

Lim IL, Johnston IW, Choi SK (1993) Stress intensity factors for semi-circular specimens under three-point bending. Eng Fract Mech 44(3):363-382. doi:10.1016/0013-7944(93)90030-v

Liu C, Knauss WG, Rosakis AJ (1998) Loading rates and the dynamic initiation toughness in brittle solids. Int $\mathrm{J}$ Fract 90(1):103-118. doi:10.1023/a:1007447603177

Liu CP, Duan QQ (2009) Meso-structure analysis on instability of dynamic fracture in rock. In: Fourth international conference on experimental mechanics, Singapore, vol 1. SPIE, p 752210. doi: $10.1117 / 12.851493$

Liu CP, Ju Y, Duan QQ (2010) Influence of internal characteristic length scale on dynamic crack propagating mechanism in rock materials. Rock Soil Mech 31(Suppl. 1):91-95

Lundberg B (1976) A split Hopkinson bar study of energy absorption in dynamic rock fragmentation. Int $\mathrm{J}$ Rock Mech Min Sci Geomech Abstr 13(6):187-197. doi:10.1016/ 0148-9062(76)91285-7

Mecholsky JJ, Mackin TJ (1988) Fractal analysis of fracture in Ocala chert. J Mater Sci Lett 7(11):1145-1147. doi:10.1007/ bf00722319 
Mindess S, Banthia N, Yan C (1987) The fracture toughness of concrete under impact loading. Cem Concr Res 17(2):231241. doi:10.1016/0008-8846(87)90106-2

Nakano M, Kishida K, Yamauchi Y, Sogabe Y (1994) Dynamic fracture initiation in brittle materials under combined mode I/II loading. J Phys IV France 04(C8):C8-695-C698-700. doi:10.1051/jp4:19948106

Nara Y, Takada M, Mori D, Owada H, Yoneda T, Kaneko K (2010) Subcritical crack growth and long-term strength in rock and cementitious material. Int J Fract 164(1):57-71. doi:10. 1007/s10704-010-9455-z

Nasseri MHB, Mohanty B (2008) Fracture toughness anisotropy in granitic rocks. Int J Rock Mech Min 45(2):167-193. doi:10. 1016/j.ijrmms.2007.04.005

Norton MG, Atkinson BK (1981) Stress-dependent morphological features on fracture surfaces of quartz and glass. Tectonophysics 77(3-4):283-295. doi:10.1016/ 0040-1951(81)90267-5

Ouchterlony F (1988) Suggested methods for determining the fracture toughness of rock. Int J Rock Mech Min 25(2):7196. doi:10.1016/0148-9062(88)91871-2

Ponson L, Auradou H, Pessel M, Lazarus V, Hulin JP (2007) Failure mechanisms and surface roughness statistics of fractured Fontainebleau sandstone. Phys Rev E 76(3):036108. doi:10. 1103/PhysRevE.76.036108

Ravi-Chandar K (2004) Dynamic fracture. Elsevier Science, Amsterdam

Ravi-Chandar K, Knauss WG (1984a) An experimental investigation into dynamic fracture: I. Crack initiation and arrest. Int J Fract 25(4):247-262. doi:10.1007/bf00963460

Ravi-Chandar K, Knauss WG (1984b) An experimental investigation into dynamic fracture: II. Microstructural aspects. Int J Fract 26(1):65-80. doi:10.1007/bf01152313

Ravi-Chandar K, Knauss WG (1984c) An experimental investigation into dynamic fracture: III. On steady-state crack propagation and crack branching. Int J Fract 26(2):141-154. doi:10. 1007/bf01157550

Ravi-Chandar K, Yang B (1997) On the role of microcracks in the dynamic fracture of brittle materials. J Mech Phys Solids 45(4):535-563. doi:10.1016/s0022-5096(96)00096-8

Rose LRF (1986) Effective fracture toughness of microcracked materials. J Am Ceram Soc 69(3):212-214. doi:10.1111/j. 1151-2916.1986.tb07409.x

Schubnel A, Fortin J, Burlini L, Guéguen Y (2005) Damage and recovery of calcite rocks deformed in the cataclastic regime. Geol Soc London Spec Publ 245(1):203-221. doi:10.1144/ gsl.sp.2005.245.01.10

Schuler H, Mayrhofer C, Thoma K (2006) Spall experiments for the measurement of the tensile strength and fracture energy of concrete at high strain rates. Int J Impact Eng 32(10):16351650. doi:10.1016/j.ijimpeng.2005.01.010

Schultz R, Jensen M, Bradt R (1994) Single crystal cleavage of brittle materials. Int J Fract 65(4):291-312. doi:10.1007/ bf00012370

Tang CA, Xu XH (1990) A new method for measuring dynamic fracture toughness of rock. Eng Fract Mech 35(4-5):783-791. doi:10.1016/0013-7944(90)90162-a

Thompson A, Knott J (1993) Micromechanisms of brittle fracture. Metall Mater Trans A 24(3):523-534. doi:10.1007/ bf02656622
Wang QZ, Feng F, Ni M, Gou XP (2011) Measurement of mode I and mode II rock dynamic fracture toughness with cracked straight through flattened Brazilian disc impacted by split Hopkinson pressure bar. Eng Fract Mech 78(12):2455-2469. doi:10.1016/j.engfracmech.2011.06.004

Wang QZ, Zhang S, Xie HP (2010) Rock dynamic fracture toughness tested with holed-cracked flattened Brazilian discs diametrically impacted by SHPB and its size effect. Exp Mech 50(7):877-885. doi:10.1007/s11340-009-9265-2

Wong LNY, Zou C, Cheng Y (2014) Fracturing and failure behavior of Carrara marble in quasistatic and dynamic Brazilian disc tests. Rock Mech Rock Eng 47(4):1117-1133. doi:10.1007/ s00603-013-0465-9

Xia K, Huang S, Dai F (2013) Evaluation of the frictional effect in dynamic notched semi-circular bend tests. Int J Rock Mech Min 62:148-151. doi:10.1016/j.ijrmms.2013.06.001

Xie H, Sanderson D (1995) Fractal effects of crack propagation on dynamic stress intensity factors and crack velocities. Int $\mathrm{J}$ Fract 74(1):29-42. doi:10.1007/bf00018573

Xie H, Wang J (1999) Direct fractal measurement of fracture surfaces. Int J Solids Struct 36(20):3073-3084. doi:10.1016/ s0020-7683(98)00141-3

Yang RS, Yue ZW, Sun ZH, Xiao TS, Guo DM (2009) Dynamic fracture behavior of rock under impact load using the caustics method. Min Sci Technol 19(1):79-83. doi:10.1016/ s1674-5264(09)60015-6

Yin ZQ, Li XB, Jin JF, He XQ, Du K (2012) Failure characteristics of high stress rock induced by impact disturbance under confining pressure unloading. Trans Nonferr Metal Soc 22(1):175-184. doi:10.1016/s1003-6326(11)61158-8

Yu Y, Zhang ZX (1995) Determining critical time of rock dynamic fracture by dynamic Moire method. J Univ Sci Technol Beijing 2(2):109-113

Zhang QB, Zhao J (2013a) Effect of loading rate on fracture toughness and failure micromechanisms in marble. Eng Fract Mech 102:288-309. doi:10.1016/j.engfracmech.2013.02.009

Zhang QB, Zhao J (2013b) Determination of mechanical properties and full-field strain measurements of rock material under dynamic loads. Int J Rock Mech Min 60:423-439. doi:10. 1016/j.ijrmms.2013.01.005

Zhang QB, Zhao J (2014) A review of dynamic experimental techniques and mechanical behaviour of rock materials. Rock Mech Rock Eng 47(4):1411-1478. doi:10.1007/ s00603-013-0463-y

Zhang XP, Wong LNY (2013) Loading rate effects on cracking behavior of flaw-contained specimens under uniaxial compression. Int J Fract 180(1):93-110. doi:10.1007/ s10704-012-9803-2

Zhang XX, Yu RC, Ruiz G, Tarifa M, Camara MA (2010) Effect of loading rate on crack velocities in HSC. Int J Impact Eng 37(4):359-370. doi:10.1016/j.ijimpeng.2009.10.002

Zhang ZX, Kou SQ, Jiang LG, Lindqvist PA (2000) Effects of loading rate on rock fracture: fracture characteristics and energy partitioning. Int J Rock Mech Min 37(5):745-762. doi:10.1016/s1365-1609(00)00008-3

Zhang ZX, Kou SQ, Yu J, Yu Y, Jiang LG, Lindqvist PA (1999) Effects of loading rate on rock fracture. Int J Rock Mech Min 36(5):597-611. doi:10.1016/s0148-9062(99)00031-5

Zhang ZX, Yu J, Kou SQ, Lindqvist PA (2001) On study of influences of loading rate on fractal dimensions of fracture surfaces 
in gabbro. Rock Mech Rock Eng 34(3):235-242. doi:10.1007/ s006030170011

Zhao J, Zhou YX, Hefny AM, Cai JG, Chen SG, Li HB, Liu JF, Jain M, Foo ST, Seah CC (1999) Rock dynamics research related to cavern development for ammunition storage. Tunn Undergr Space Technol 14(4):513-526. doi:10. 1016/s0886-7798(00)00013-4

Zhao Y, Zhao G-F, Jiang Y (2013) Experimental and numerical modelling investigation on fracturing in coal under impact loads. Int J Fract 183(1):63-80. doi:10.1007/ s10704-013-9876-6

Zhou F, Molinari J-F, Shioya T (2005) A rate-dependent cohesive model for simulating dynamic crack propagation in brittle materials. Eng Fract Mech 72(9):1383-1410. doi:10.1016/j. engfracmech.2004.10.011
Zhou HW, Xie H (2003) Direct estimation of the fractal dimensions of a fracture surface of rock. Surf Rev Lett 10(5):751762. doi:10.1142/S0218625X03005591

Zhou YX, Xia K, Li XB, Li HB, Ma GW, Zhao J, Zhou ZL, Dai F (2012) Suggested methods for determining the dynamic strength parameters and mode-I fracture toughness of rock materials. Int J Rock Mech Min 49:105-112. doi:10.1016/j. ijrmms.2011.10.004 